
\title{
S Research Square \\ Preparation of Polyaniline Nanofibers And Experimental Study On Their Electrochemical Properties And Conductivity
}

Uihoa chg ( 487305109@qq.com )

Institute of Tibetan Plateau Research

\section{Research Article}

Keywords: nano, conductivity, materials, oxygen

Posted Date: September 22nd, 2021

DOl: https://doi.org/10.21203/rs.3.rs-903480/v1

License: (c) (i) This work is licensed under a Creative Commons Attribution 4.0 International License.

Read Full License 


\section{Abstract}

Among nano polyaniline materials, polyaniline nanofibers are the most important. The low conductivity and poor processability have become the biggest obstacles to the application of polyaniline as a practical material. The excellent characteristics of new polyaniline nanofiber materials can just overcome the shortcomings of Polyaniline in forming and processing. In this study, a new polyaniline nanofiber was prepared by chemical oxidation, its structure was characterized, the mechanism of improving its conductivity was studied, and its superior electrocatalytic activity was evaluated by Electrochemical performance test. The results show that the diameter of polyaniline nanofibers is $20 \mathrm{~nm} \sim 50 \mathrm{~nm}$ and the fiber length is $2 \mu \mathrm{m} \sim 5 \mu \mathrm{m}$. The structure is uniform and the conductivity can reach $13.5 \mathrm{~S} / \mathrm{cm}$. he electrocatalytic activity of polyaniline nanofibers for oxygen evolution and chlorine evolution was systematically tested. It was found that the electrocatalytic activity of polyaniline nanofibers for oxygen evolution was higher than that of polyaniline nanofibers. The electrocatalytic activity of carbon paper electrode prepared by $\beta-\mathrm{PbO}_{2}$ nano powder is superior to that of traditional chlorine evolution anode $\mathrm{Ti} / \mathrm{RuO}_{2}$.

\section{Instruction}

The structural size of materials is an important factor affecting their physical and chemical properties. Studies in the past few decades have found that some commonly used materials will show some strange physical and chemical properties if their structural size is reduced to the nanometer level, because these special properties have broad potential applications in various fields, Nanotechnology has attracted unprecedented attention ${ }^{[1]}$.Polyaniline, as one of the earliest conductive polymer materials, is considered to be the most likely conductive polymer material to be put into practical application on a large scale because of its simple preparation process, low cost, good environmental stability and high conductivity. At present, a series of nano polyaniline materials such as polyaniline nanoparticles, polyaniline nanobelts, polyaniline nanofibers, polyaniline nanotubes and polyaniline nanocomposites have been prepared $^{[2]}$. At the same time, the methods and processes for preparing nano

polyaniline materials have also been developed. At present, there are hard template method, soft template method, very dilute solution method, interfacial polymerization method, self-assembly method and electropolymerization method ${ }^{[3]}$.

Nano polyaniline has better physical and chemical properties and wider application prospects than general powder polyaniline. For example, nano polyaniline has a large working area and a short diffusion distance of target molecules, which makes the sensing sensitivity, accuracy and reaction speed of nano polyaniline material better than general powder polyaniline. Therefore, nano polyaniline as sensing material is more ideal than general powder polyaniline ${ }^{[4]}$.In addition, the materials composed of nano polyaniline have a relatively tight structure, and there are more binding points between polyaniline molecular chains, which makes nano polyaniline materials show excellent properties in related electronic devices, such as electronic devices, electrochemical components, energy storage equipment, 
optoelectronic components, etc. Further research also found that the molecular structure of nano polyaniline has high molecular crystallinity and regularity of molecular arrangement. Such molecular structure is also conducive to improve the conductivity of intrinsic polyaniline ${ }^{[5,6]}$, which is the basis of using polyaniline as an electroactive material.

Nanofiber materials have a large aspect ratio, which is conducive to the movement of electrons along the fiber direction, avoid more transitions in the transmission process, and improve the conductivity of materials. This property is very important for polyaniline.

Previous studies have found that the properties of conductive polymers can be changed by cellulose and its derivatives to achieve some special functions ${ }^{[7,8]}$. Because cellulose and its derivatives have flexible molecular structure, unique supramolecular configuration and inherent strength, it is an ideal template for the polymerization of conductive polymers with nanostructures. For example, gas sensitive nano polyaniline was synthesized in acetone solution with cellulose acetate as template ${ }^{[9,10]}$; Sodium shuttle methylcellulose has also been used as a polymerization template to synthesize polyaniline/sodium shuttle methylcellulose nanorods ${ }^{[11]}$; Conductive polymer films have been prepared with cellulose as the matrix component ${ }^{[8]}$; Nanofiber polypyrrole composites were also successfully prepared ${ }^{[12]}$.

In this study, polyaniline nanofibers were synthesized by chemical oxidation method with ethyl cellulose as template. The environmental stability, electrical properties, SEM, TEM, XRD, electrocatalytic activities of oxygen and chlorine evolution of the polyaniline nanofibers were measured, and the essential reasons for their electrochemical properties were analyzed.

\section{Experiment}

\subsection{Preparation of polyaniline nanofibers}

The preparation methods of polyaniline mainly include chemical oxidation, electrochemical polymerization, solid oxidation and so on ${ }^{[13]}$. Among them, the chemical oxidation method has simple test equipment, easy control of the experimental process, short process flow and high preparation efficiency, which is suitable for large-scale production ${ }^{[14]}$. In this experiment, polyaniline nanofiber materials required for the experiment are prepared by chemical oxidation method. The experimental flow chart is shown in Figure 1. The aniline in the experiment shall be subject to secondary distillation, and the water for preparing the solution shall be subject to secondary distillation. The product obtained from the reaction shall be cleaned with ethanol and then acetone until the cleaning solution is clear.

The factors affecting the preparation of polyaniline by chemical oxidation were studied in detail, such as the initial $\mathrm{pH}$ value of the preparation system, the type of oxidant, the ratio of the amount of oxidant to the amount of aniline, the reaction temperature, the concentration of aniline, and the subsequent treatment process $^{[15]}$. 


\subsection{Conductivity stability test of polyaniline nanofibers}

Determination of conductivity and temperature stability of polyaniline: polyaniline powder is pressed into a circular sample with a diameter of $10 \mathrm{~mm}$ and a thickness of $3 \mathrm{~mm}$ by a manual hydraulic press under a pressure of 20MPa. Select two silver wires, bend one end of each silver wire into a compass shape, and keep the other end straight; One end of the silver wire bent into a compass shape is bonded to one side of the polyaniline sheet sample with conductive silver paste, and the other end of the compass shape of the other silver wire is bonded to the other side of the polyaniline sheet; Finally, connect the other straight wires at both ends of the silver wire between the two polar plates as shown in Figure 2, and prepare to measure the change of its conductivity with temperature.

In the device for measuring the conductivity of polyaniline shown in Figure 2, the closed hole cavity where the sample is placed is a device that can be heated, and the sample can be heated to measure the conductivity of the sample at different temperatures. Another conductivity test device in the figure is the electrochemical workstation, because the electrochemical workstation can provide a relatively stable power supply current and test the corresponding voltage. According to the measurement results, the conductivity can be calculated by using formulas

$\sigma=\frac{1}{\rho}$ and $\mathrm{R}=\rho \frac{L}{S}$.

\subsection{Electrochemical performance test of polyaniline nanofibers}

\subsubsection{Preparation of polyaniline nanofiber test electrode}

Preparation of blank carbon paper electrode: the carbon paper is cut into $12 \mathrm{~cm} \times 1 \mathrm{~cm}$, and one end of the carbon paper is encapsulated with epoxy resin to expose only one working surface of $1 \mathrm{~cm} \times 1 \mathrm{~cm}$.

Preparation of carbon paper electrode loaded with polyaniline Nanofibers: grind the prepared polyaniline nanofibers and an appropriate amount of diluted Nafion solution in an agate mortar to a fully evenly dispersed viscous flow material with good fluidity, then evenly coat the viscous flow material on the $1 \mathrm{~cm} x$ $1 \mathrm{~cm}$ working surface of conductive carbon paper, and dry it in an oven at $45^{\circ} \mathrm{C}$ for 6 hours to prepare an electrode for measurement.

Load preparation of carbon paper electrode of $\beta-\mathrm{PbO}_{2}$ nano powder: the preparation method is the same as that of carbon paper electrode loaded with polyaniline nano fiber, The quality of $\beta-\mathrm{PbO}_{2}$ nanopowder is the same as that of polyaniline nanofiber.

\subsubsection{Test of electrocatalytic activity of polyaniline nanofibers for oxygen and chlorine evolution}

The oxygen evolution characteristics were measured in sulfuric acid system and chlorine evolution characteristics were measured in chloride system and electrodeposition drilling system. The anodic 
polarization curves and cyclic voltammetry curves of the samples were measured; The characteristics of oxygen and chlorine evolution of carbon paper electrode loaded with polyaniline nanofibers were compared with those of comparison electrode, and the electrocatalytic characteristics of oxygen and chlorine evolution of polyaniline nanofibers were obtained.

\section{Results And Discussion}

\subsection{Microstructure of polyaniline nanofibers 3.1.1 Morphological characteristics of polyaniline nanofibers}

In order to characterize the prepared polyaniline nanofibers on the microstructure, the SEM images (Fig. 3) and the SEM images of template free polyaniline (Fig. 4) were tested.

\section{SEM diagram}

It can be seen from the SEM diagram of Fig. 16 that the synthesized polyaniline nanofibers have uniform size and shape, staggered fibers, and the diameter of nanofibers is about $20 \mathrm{~nm}$ to $50 \mathrm{~nm}$ (Fig. 3b). TEM image of polyaniline nanofibers (Fig. $5 \mathrm{~B}$ ). From the transmission electron microscope, it can be found that the nanofibers are aggregated by smaller polyaniline particles.

In order to determine the role of the template, the scanning electron microscope of the sample prepared by the template free method was performed (Fig. 4). Comparing the TEM Fig. 5A and Fig. 5B, we can find the growth mechanism of synthesizing polyaniline by template free method ${ }^{[16]}$ : because there is no template, polyaniline gradually grows from the nucleus generated at the initial stage of polymerization and forms a granular structure; When there is a template, in the reaction process, due to the electrostatic force, the Polymerized Polyaniline molecular chain grows along the template. This expansion finally promotes the synthesis of nanofibers.

૫ TEM image

\subsubsection{Formation mechanism of polyaniline nanofibers}

Although the growth process of polyaniline nanofibers is complex, the ethyl cellulose template significantly affects the growth process of polyaniline nanofibers (as shown in Fig. 3 and Fig. 4). The formation mechanism of polyaniline nanofibers can be discussed as follows.

Firstly, ethyl cellulose was dissolved in alcohol. Under intense magnetic stirring, the solution of ethyl cellulose was combined with aqueous aniline solution, and the hydrochloric acid concentration of the mixture was adjusted to $1 \mathrm{~mol} / \mathrm{L}$ by adding concentrated $\mathrm{HCl}$; The ethyl cellulose solution is then mixed 
into the reactant, and the mixture becomes turbid. The diameter of the fiber of ethyl cellulose is $2 \mathrm{~nm}$ to $20 \mathrm{~nm}$, and its length is several microns ${ }^{[17]}$. In this process, it is considered that ethyl cellulose acts as a hydrophobic material similar to other template methods for the synthesis of polyaniline.

It has been found from previous studies that the role of hydrophobic surface in aniline polymerization system is the same as that of interface polymerization ${ }^{[18]}$, and the hydrophobic surface will change the dielectric constant of aqueous medium and aniline, which creates a nuclear generation condition for the generation of nanofibers ${ }^{[19,20]}$. In this experiment, under the action of electrostatic force, aniline ions adhere to the hydrophobic surface of ethyl cellulose. At the beginning of polymerization, polyaniline nuclei are formed on the surface of ethyl cellulose. When the polymerization reaction is carried out, the nuclei of polyaniline nanofibers are generated along the surface of cellulose. Under the action of electrostatic force, the newly generated polyaniline adheres to the surface of ethyl fiber, so as to promote the synthesis of polyaniline nanofibers. Finally, the obtained product is washed and filtered with alcohol and acetone, so that the ethyl cellulose as a template will be dissolved and removed from the product to obtain pure polyaniline nanofibers. Thus, polyaniline nanofibers can be synthesized using ethyl cellulose as a template. The formation mechanism is shown in Fig. 6.

\subsubsection{Molecular structure and characterization of polyaniline nanofibers}

The molecular structure and crystallinity of polyaniline nanofibers were characterized by FTIR (Fig. 7) and X-ray diffraction (Fig. 8), respectively, and then compared with traditional polyaniline. The FTIR spectrum shows that polyaniline and polyaniline nanofibers have the same characteristic peak (Fig. 7). The functional group structure represented by the characteristic absorption peak of hydrochloric acid doped polyaniline is as follows: $1558 \mathrm{~cm}^{-1}$ and $1477 \mathrm{~cm}^{-1}$ are the stretching vibration of ketone formula $(\mathrm{C}=\mathrm{C})$ and benzene formula (C-C) in polyaniline chain, respectively; $1296 \mathrm{~cm}^{-1}$ and $1240 \mathrm{~cm}^{-1}$, which are respectively the telescopic vibration in awake and benzene structures $(C-C) ; 795 \mathrm{~cm}^{-1}$ is the out of plane bending vibration of the corresponding substituted $\mathrm{C}-\mathrm{H}$ bond of the benzene ring on the Aniline Unit ${ }^{[21]}$. Comparing (a) and (b) in Fig. 7, it can be seen that the position of the main absorption peak has not changed, which shows that the molecular structure of polyaniline prepared with ethyl cellulose as template is the same as that of traditional polyaniline PANI-HCl. From the FTIR spectrum of ethyl cellulose in the comparison figure (Fig. 7), it can also be seen that the final polyaniline nanofibers no longer contain the component of ethyl cellulose.

The wide-angle X-ray diffraction patterns of polyaniline nanofibers and polyaniline powder synthesized by conventional methods are shown in Fig. 8 . The curves of the two samples have four different crystallization peaks: $25.53^{\circ}, 20.74^{\circ}, 15.52^{\circ}$ and $8.80^{\circ}$. The peak value is $25.53^{\circ}$. It is the characteristic crystallization peak of hydrochloric acid doped polyaniline ${ }^{[22]}$, which comes from the periodic structure perpendicular to the polyaniline chain. The other sharp peak of $20.74^{\circ}$ is due to the parallel periodic structural contribution of the polymer chain ${ }^{[23]}$. The peak at $15.52^{\circ}$ and $8.80^{\circ}$ indicates that the particle 
size of the main chain polyaniline is about $10 \mathrm{~nm}^{[24]}$, which can also be seen from the TEM image of Fig. 18.

X-ray diffraction results show that the diffraction peaks of polyaniline nanofibers have relatively high intensity. The relatively strong diffraction peak corresponds to the amount of polyaniline with higher diffraction surface per unit volume, so the volume fraction of crystalline phase of polyaniline nanofibers is large and the crystallinity is high.

The conductivity of polyaniline nanofiber sample is significantly higher than that of polyaniline sample synthesized by conventional method. Stejskaletal ${ }^{[25]}$ prepared PANI HCl sample by using $\left(\mathrm{NH}_{4}\right)_{2} \mathrm{~S}_{2} \mathrm{O}_{8}$ as oxidant and oxidizing aniline hydrochloride in aqueous medium at room temperature. The conductivity of the sample at room temperature is $4.4 \pm 1.7 \mathrm{~S} / \mathrm{cm}$. Under the same conditions, the conductivity of polyaniline nanofibers prepared in this study is $13.5 \mathrm{~S} / \mathrm{cm}$. This difference is due to the difference in the microstructure of the two samples. The results of SEM, TEM and X-ray diffraction show that the crystallinity of polyaniline nanofibers is higher than that of PANI synthesized by conventional method, and the molecular structure shows more regularity, making the carrier move more smoothly along the molecular chain; In addition, the high crystallinity indicates that the polyaniline nanofibers per unit volume contain more "islands" with high conductivity, which makes the transition of electrons between these "islands" more efficient. Therefore, polyaniline nanofibers have higher conductivity than polyaniline prepared by conventional method.

\subsubsection{Particle size distribution of polyaniline nanofibers}

Figure 9 is a comparison diagram of the particle size distribution of polyaniline nanofibers synthesized in this experiment and the particle size of Polyaniline and ethyl cellulose synthesized by conventional method. As shown in the figure, the experimentally prepared polyaniline nanofibers have a length of 3 microns to 5 microns, of which $60 \%$ of the particles have a length of 3.3 microns. The particle size distribution curve of ethyl cellulose sample and the comparison of polyaniline nanofibers show that the size distribution of polyaniline nanofibers is similar to the template size of ethyl cellulose. This result confirms the assumption that polyaniline molecules are deposited along the ethyl cellulose template. At the same time, the distribution curve of PANI samples synthesized by conventional method shows that the particle size distribution of polyaniline synthesized by conventional method has a wide distribution. Polyaniline particles exist in the range from 2 microns to 30 microns, and the particle size is not uniform.

\subsection{Stability of polyaniline nanofibers}

\subsubsection{Thermal stability}

The degradation of polymer molecules, the strength of interaction between molecules, the aging of polymer and the stability of polymer properties are greatly related to temperature. Polyaniline nanofibers have experienced four obvious stages in the degradation process. 
The first stage is the stage when the temperature is less than $150^{\circ} \mathrm{C}$, the weight loss rate is slow, the temperature change is stable, and the overflow of water and doped ions in polyaniline occurs; In the second stage, the temperature is between $150^{\circ} \mathrm{C} \sim 266^{\circ} \mathrm{C}$. At this stage, the main chain structure of polyaniline is relatively stable, mainly due to the overflow of doped ions. At the same time, with the crosslinking of polymer molecules, the crystalline state decreases. The third stage is mainly when the temperature is greater than $266^{\circ} \mathrm{C}$. At this time, with the increase of temperature, there is an obvious exothermic process. Chemical reactions such as cross-linking and oxidative fracture between polyaniline molecular chains occur, resulting in the complete loss of crystallinity ${ }^{[26,27]}$; The fourth stage mainly refers to the temperature greater than $900^{\circ} \mathrm{C}$. At this time, it can be seen from the thermogravimetric diagram that the quality of the carbonized product of polyaniline will not change, that is, the obtained product will not undergo degradation or decomposition reaction in the air, and the quality of the material is stable. It can be seen that the PANI-HCl sample is stable at a temperature less than $150^{\circ} \mathrm{C}$.

\subsubsection{Product analysis of polyaniline thermal degradation process}

Through the elemental analysis and XPS analysis of the heat drop products of polyaniline ${ }^{[28]}$, it is obtained that the basic process of the de doping reaction of polyaniline at the initial stage of heating (less than $200^{\circ} \mathrm{C}$ ) is shown in Fig. 10 below. At this stage, the dehydration and de doping reaction of polyaniline molecules mainly occur.

When the temperature is between $200^{\circ} \mathrm{C} 400{ }^{\circ} \mathrm{C}$, the crosslinking of polyaniline molecules begins to take place $^{[29,30]}$. The molecular formula of the crosslinking reaction is shown in Fig. 11 below. In this stage, the crosslinking reaction of polyaniline molecules and the breaking reaction of some molecular chains mainly take place.

In the air atmosphere, when the temperature rises to $300^{\circ} \mathrm{C} \sim 600^{\circ} \mathrm{C}$, the polyaniline molecule begins to break, and the benzene ring and quinone ring open ${ }^{[31]}$, corresponding to the third and fourth structures in Fig. 12 below. The reaction at this stage mainly focuses on the molecular skeleton, and the product is nitrogen doped carbon material obtained from the pyrolysis of polyaniline.

\subsubsection{Acid and alkali environmental stability of polyaniline nanofibers}

It is found that polyaniline nanofibers are unstable in the environment of $\mathrm{pH}>7$, and de doping will occur, which makes the conductivity of polyaniline decrease rapidly, and the instability of polyaniline becomes more and more serious with the increase of alkaline strength. Polyaniline is stable in acidic environment.

In an acidic environment, if the anions in the environmental medium are different from those of polyaniline doped acid, the exchange of doped acid cations will occur ${ }^{[32]}$. Figure 13 shows the cyclic voltammetry curve measured at a scanning rate of $20 \mathrm{mV} / \mathrm{s}$ in the range of $-0.9 \mathrm{~V} \sim+0.9 \mathrm{~V}$ in $1 \mathrm{~mol} / \mathrm{L}$ $\mathrm{H}_{2} \mathrm{SO}_{4}$ aqueous solution with mercurous sulfate electrode (MSE) as the reference electrode. It can be 
seen that when the number of cycles increases, the redox peak of the cycle is constantly changing, which is the result of the exchange between sulfate ions in sulfuric acid and chloride ions in polyaniline. Although such ion exchange phenomenon will not make polyaniline lose its electrical activity, it will introduce the doped ion component of polyaniline into the test electrolyte.

\subsection{Electrochemical catalytic properties of polyaniline nanofibers}

The electrocatalytic activity of polyaniline was first found that polyaniline loaded with platinum particles can accelerate the oxidation of small molecular organics ${ }^{[33]}$; Later, it was found that polyaniline composite with carbon nanotubes ${ }^{[34]}$, composite with graphene ${ }^{[35]}$, composite with $\mathrm{C}_{60}{ }^{[36]}$, composite with inorganic semiconductor materials ${ }^{[37]}$ and other materials have excellent electrocatalytic properties. The prepared electrode materials can be used in electrochemical processes such as fuel cells, electrocatalytic degradation of organics, electrochemical synthesis of organics, solar cells and so on.

In recent years, there have been many studies on the electrocatalytic activity of the composites formed by nitrogen doped carbon materials and alkali metal oxides produced by the pyrolysis of polyaniline ${ }^{[38]}$. The research on the electrochemical properties of pure polyaniline materials mainly focuses on the redox characteristics ${ }^{[39]}$, capacitance characteristics ${ }^{[40]}$ and anti-corrosion characteristics and mechanism of polyaniline on various metal materials ${ }^{[41]}$. In this paper, polyaniline nanofibers doped with hydrochloric acid were prepared, and the electrocatalytic activity of polyaniline nanofibers for oxygen and chlorine evolution was studied by electrochemical method. The essence of oxygen and chlorine evolution activity of polyaniline nanofibers was analyzed.

\subsubsection{Redox characteristics of polyaniline nanofibers in sulfuric acid system}

As shown in Fig. 14, in order to investigate the redox characteristics of polyaniline nanofibers between $0.9 \mathrm{~V} \sim+0.9 \mathrm{~V}$, the cyclic voltammetry curves of carbon paper electrode and blank carbon paper electrode loaded with polyaniline nanofibers were measured. It can be seen that the carbon paper electrode loaded with conductive polyaniline nanofibers shows good redox characteristics, which is mainly caused by the doping and de doping reaction of doped anions and $\mathrm{H}^{+}$ions in polyaniline ${ }^{[42]}$. Previous studies have found that in the cyclic voltammetry curve of conductive polyaniline materials, The positions of oxidation and reduction peaks are related to the $\mathrm{pH}$ value of the test environment. At the same time, the studies of B.palys and P.celuch also show that there is a reduction peak in the cyclic voltammetry of polyaniline nano materials, which should appear at about $-0.2 \mathrm{~V}^{[43]}$, which is different from the non nano polyaniline materials synthesized by conventional method ${ }^{[44]}$. The polyaniline prepared in this experiment is nanofibrous polyaniline, so there is a reduction peak at $-0.2 \mathrm{~V}$. In addition, there are only two groups of redox peaks in Fig. 14, indicating that in the prepared polyaniline material, the amount of phenazine ring produced by the cross-linking between polyaniline molecular chains is small, which is not enough to 
produce an intermediate peak between the oxidation peak and the reduction peak ${ }^{[45]}$. The prepared polyaniline is relatively pure, so two pairs of redox peaks are seen on the cyclic voltammetry. According to cyclic voltammogram(Fig. 14) and the previous analysis, we can get: $₫$ nano polyaniline material is prepared; $₫$ The prepared nano polyaniline material showed higher redox properties than blank carbon paper.

\subsubsection{Oxygen evolution anodic polarization curve of polyaniline nanofibers}

$\beta-\mathrm{PbO}_{2}$ is recognized as a material with good oxygen evolution catalytic activity ${ }^{[46]}$, and the same quality as polyaniline was selected in the experiment $\beta-\mathrm{PbO}_{2}$ nano powder was prepared by the same method as the carbon paper electrode loaded with polyaniline Carbon paper electrode of $\beta-\mathrm{PbO}_{2}$ nano powder. The oxygen evolution anodic polarization curves of several electrodes were measured under the condition of oxygen evolution, as shown in Fig. 15

We can see that under the same oxygen evolution voltage, the oxygen evolution current density of carbon paper electrode loaded with polyaniline is much greater than that of blank carbon paper and load oxygen evolution current density of carbon paper electrode with $\beta-\mathrm{PbO}_{2}$ nano powder. Since carbon paper is used as the base material for preparing the electrode, but the electroactive catalysts are different, it can be concluded from Fig. 15 that due to the high oxygen evolution catalytic activity of polyaniline, the oxygen evolution catalytic performance of carbon paper loaded with polyaniline nanofibers is better than that of blank carbon paper and loaded carbon paper The carbon paper electrode of $\beta-\mathrm{PbO}_{2}$ nano powder is much improved.

In the oxygen evolution state, the kinetic parameters of electrode oxygen evolution can be determined according to tafel formula $\eta=\mathrm{b}+\log i^{[47]}$. The strong polarization region of each electrode is selected in the experiment: the selection potential range of blank carbon paper electrode is $1.6 \mathrm{~V} \sim 1.8 \mathrm{~V}$; The selective potential range of carbon paper electrode loaded with polyaniline: 1.4V 1.7V; load The selective potential range of carbon paper electrode of $\beta-\mathrm{PbO}_{2}$ nano powder is $1.7 \mathrm{~V} \sim 1.9 \mathrm{~V}$; Fig. 16 shows the relationship between steady-state oxygen evolution overpotential $\eta \sim \log i$ of three different anode materials under oxygen evolution state. It can be seen that when the oxygen evolution current density increases, the value of oxygen evolution overpotential also increases, but the slope of carbon paper electrode loaded with polyaniline nanofibers is the smallest, and the increase rate of overpotential is the slowest.

Table 1 lists the oxygen evolution kinetic parameters of the steady-state oxygen evolution process corresponding to the three electrode materials, $i^{0}$ refers to the apparent exchange current density of the electrode. It can be seen from Table 1 that when the apparent exchange current density is the same order of magnitude, the $A$ and $b$ values of carbon paper electrode loaded with polyaniline nanofibers are the smallest, according to tafel formula $\eta=\mathrm{b}+\log i$, we can know that corresponding to the same apparent exchange current density $i^{0}$, the smaller $\mathrm{A}$ and $\mathrm{b}$ values correspond to the smaller oxygen evolution 
overpotential. In addition, the $b$ value is inversely proportional to the electron transfer coefficient on the electrode surface. The brighter the $b$ value is, the easier the electron transfer on the electrode surface is to be realized, and the catalytic activity of the electrode is better. Therefore, the $b$ value of the carbon paper electrode loaded with polyaniline nanofibers is the smallest, and its catalytic activity is higher than that of the loaded carbon paper electrode Carbon paper electrode of $\beta-\mathrm{PbO}_{2}$ nano powder and blank carbon paper electrode.

Table 1

Kinetic parameters of oxygen evolution about the three anodes (PANI on carbon paper, $\beta-\mathrm{PbO}_{2}$ on carbon paper and bare carbon paper)

\begin{tabular}{|c|c|c|c|}
\hline Anode material & $\mathrm{a} / \mathrm{V}$ & $\mathrm{b} / \mathrm{V}$ & $i^{0} / \mathrm{A} \cdot \mathrm{cm}^{-2}$ \\
\hline Carbon paper electrode loaded with polyaniline nanofibers & 1.40211 & 0.5488 & $2.792 \times 10^{-3}$ \\
\hline Carbon paper electrode loaded with $\beta-\mathrm{PbO} 2$ nano powder & 2.45402 & 0.9569 & $2.729 \times 10^{-3}$ \\
\hline Blank carbon paper electrode & 1.82703 & 0.86912 & $7.899 \times 10^{-3}$ \\
\hline
\end{tabular}

\subsubsection{Redox properties of polyaniline nanofibers in chlorinated systems}

Figure 17 shows the cyclic voltammetry curves of carbon paper electrode loaded with polyaniline nanofibers and blank carbon paper electrode measured in an aqueous solution of $\mathrm{CoCl}_{2}$ with $\mathrm{CO}^{2+}$ concentration of $100 \mathrm{~g} / \mathrm{L}$, temperature $\mathrm{T}=60^{\circ} \mathrm{C}, \mathrm{pH}=4$.

It can be seen from the figure that in the potential range of $-0.9 \mathrm{~V} \sim+0.9 \mathrm{~V}$, in the chlorinated object system, compared with the blank carbon paper electrode, the carbon paper loaded with polyaniline shows strong redox characteristics. In cyclic voltammogram(Fig. 17), there is a significant oxidation peak at $-0.103 \mathrm{~V}$. Through analysis, it is found that the peak is composed of two parts. One is that there is $\mathrm{CO}^{2+}$ in the test environment, and the standard electrode potential value of $\mathrm{CO}^{2+} / \mathrm{CO}$ is $-0.277 \mathrm{~V}$. Therefore, when the drilling ions in the solution are reduced, a current peak should be generated near this potential. Second, when the $\mathrm{pH}$ value is 4 , The oxidation of polyaniline itself produces a current peak near $-0.103 \mathrm{~V}$, so the result of the two effects is that a more obvious oxidation current peak is produced at $-0.103 \mathrm{~V}$.

\subsubsection{Chlorine evolution anodic polarization curve of polyaniline nanofibers}

As shown in Fig. 18, $\mathrm{Ti} / \mathrm{RuO}_{2}$, a titanium based oxide nail coated electrode, was selected as the comparison electrode for chlorine evolution, and the chlorine evolution anodic polarization curves of several electrodes were measured under the condition of chlorine evolution. It can be seen from Fig. 18 
that under the same chlorine evolution current density, the chlorine evolution overpotential of $\mathrm{Ti} / \mathrm{RuO}_{2}$ is the lowest, followed by blank carbon paper, and finally the carbon paper electrode loaded with polyaniline nanofibers. It can be seen from here that the potential of carbon paper loaded with polyaniline nanofibers is higher than that of blank carbon paper, indicating that the catalytic effect of polyaniline nanofibers is not as high as that produced during oxygen evolution, and even hinders the chlorine evolution of carbon paper. It can also be seen from Fig. 18 that the carbon paper electrode loaded with polyaniline has a current value between $0.12 \mathrm{~V}$ and $1.35 \mathrm{~V}$, and the current value can reach the maximum value of $0.05 \mathrm{~A} / \mathrm{cm}^{2}$, which is mainly due to the current value generated by the self oxidation reaction of Polyaniline in this potential range, which can also be seen from the cyclic voltammogram of the chlorinated object system in Fig. 17.

In the chlorine evolution state, the strong polarization region of each electrode is selected to numerically fit the polarization kinetic parameters, in which the selection potential range of blank carbon paper electrode is $1.25 \mathrm{~V} \sim 1.55 \mathrm{~V}$; The selective potential range of carbon paper electrode loaded with polyaniline is $1.35 \mathrm{~V} \sim 1.65 \mathrm{~V}$; The selective potential range of $\mathrm{Ti} / \mathrm{RuO}_{2}$ electrode is $1.3 \mathrm{~V} \sim 1.5 \mathrm{~V}$; Fig. 19 shows the chlorine evolution overpotential of three different anode materials in the chlorine evolution state $\eta \sim \log i$ diagram.

The values of $\mathrm{a}, \mathrm{b}$ and $i^{0}$ in the tafel formula obtained by fitting are listed in Table 2 . It can be seen from Fig. 19 that under the same current density, the chlorine evolution overpotential of carbon paper electrode loaded with polyaniline is the highest, indicating that polyaniline nanofibers have no advantages over traditional chlorine evolution anode $\mathrm{Ti} / \mathrm{RuO}_{2}$.

Corresponding to the same change of current density, the change of chlorine evolution potential produced by carbon paper electrode loaded with polyaniline nanofibers is the largest, which shows that the chlorine evolution catalytic activity of polyaniline nanofibers is small. This conclusion can also be seen from the chlorine evolution kinetic parameters of the three electrode materials. As shown in Table 2, the value of the electrode apparent exchange current density $\left(i^{0}\right)$ corresponding to the carbon paper electrode loaded with polyaniline nanofibers is one order of magnitude smaller than that of the other two electrodes. The apparent exchange current density represents the difficulty of electrode reaction. It shows that the electrocatalytic activity of polyaniline nanofibers for chlorine evolution is lower than that of traditional chlorine evolution anode material $\mathrm{Ti}^{\mathrm{RuO}} \mathrm{R}_{2}$. 
Table 2

Kinetic parameters of chlorine evolution about the three anodes (PANI on carbon paper, $\mathrm{Ti} / \mathrm{RuO}_{2}$ and bare carbon paper)

\begin{tabular}{|llll|}
\hline Anode material & a/V & b/V & $\mathbf{i}^{\mathbf{0}} / \mathbf{A} \cdot \mathbf{c m}^{-2}$ \\
\hline Polyaniline nanofiber carbon paper electrode & 149.7 & 226.8 & 374.5 \\
\hline${\mathrm{Ti} / \mathrm{RuO}_{2} \text { anode }}^{-137.7}$ & 237.6 & 345.8 \\
\hline Blank carbon paper & 120.5 & 236.5 & 373.7 \\
\hline
\end{tabular}

\section{Conclusions}

(1). The microstructure, molecular structure, crystalline state and conductivity of polyaniline nanofibers were characterized. The results show that the diameter of polyaniline nanofibers is $20 \mathrm{~nm} \sim 50 \mathrm{~nm}$ and the fiber length is $2 \mu \mathrm{m} \sim 5 \mu \mathrm{m}$. The structure is uniform and the conductivity can reach $13.5 \mathrm{~S} / \mathrm{cm}$. The mechanism of preparing polyaniline nanofibers with ethyl cellulose as template was discussed.

(2). Taking PANI-SA and PANI-MSA as comparison objects, the temperature stability, the relationship between conductivity and temperature, and the relationship between crystallization and temperature were studied. It was obtained that the processing temperature of PANI-HCl nanofibers could reach $150^{\circ} \mathrm{C}$, and the heating treatment of $100^{\circ} \mathrm{C}$ was conducive to improve the conductivity of polyaniline materials. The degradation law and mechanism of polyaniline under temperature were studied. The variation of conductivity with temperature further confirms that the conductivity mode of polyaniline nanofibers is dominated by variable range jump (VRH) model.

(3). The electrocatalytic activity of polyaniline nanofibers for oxygen evolution and chlorine evolution was systematically tested. It was found that the electrocatalytic activity of polyaniline nanofibers for oxygen evolution was higher than that of polyaniline nanofibers. The electrocatalytic activity of carbon paper electrode prepared by $\beta-\mathrm{PbO}_{2}$ nano powder is superior to that of traditional chlorine evolution anode $\mathrm{Ti} / \mathrm{RuO}_{2}$.

\section{Declarations}

\section{Conflicts of interest}

There are no conflicts to declare.

\section{References}

1. Wan, M. Some Issues Related to Polyaniline Micro-/Nanostructures. Macromol. Rapid Commun, 30, 963-975 (2009). 
2. Ates, M. A review study of (bio)sensor systems based on conducting polymers. Materials Science \& Engineering C-Materials for Biological Applications, 33, 1853-1859 (2013).

3. Wolter, A., Rannou, P., Travers, J. P., Gilles, B. \& Djurado, D. Model for aging in $\mathrm{HCl}$-protonated polyaniline: Structure, conductivity, and composition studies. Phys. Rev. B, 58, 7637 (1998).

4. Rahy, A. \& Yang, D. J. Synthesis of highly conductive polyaniline nanofibers. Mater. Lett, 62, 43114314 (2008).

5. Shi, Z. J. et al. In situ nano-assembly of bacterial cellulose-polyaniline composites. RSC Adv, 2, 1040-1046 (2012).

6. Russler, A., Sakakibara, K. \& Rosenau, T. Cellulose as matrix component of conducting films., 18, 937-944 (2011).

7. Zhang, L. et al. Nonaqueous synthesis of uniform polyaniline nanospheres Via cellulose acetate template. J. Polym. Sci., Part A: Polym. Chem, 50, 912-917 (2012).

8. Qaiser, A. A., Hyland, M. M. \& Patterson, D. A. Surface and Charge Transport Characterization of Polyaniline-Cellulose Acetate Com- posite Membranes. Journal of Physical Chemistry B, 115, 16521661 (2011).

9. Peng, H. et al. In situ synthesis of polyaniline/sodium carboxymethyl cellulose nanorods for highperformance redox supercapacitors. Journal of Power Sources, 211, 40-45 (2012).

10. Nystrom, G. et al. A Nanocellulose Polypyrrole Composite Based on Microfibrillated Cellulose from Wood. Journal of Physical Chemistry B, 114, 4178-4182 (2010).

11. Sambhu BhadraDipak Khastgir,Nikhil, K., Singha, J. H. \& Lee Progress in preparation, processing and applications of polyaniline,Progress in Polymer Science,2009,34,783-810.

12. Zhang, X., Warren, J., Goux, Sanjeev, K. \& Manohar Synthesis of Polyaniline Nanofibers by "Nanofiber Seeding". Journal of the American Chemical Society, 126, 4502-4503 (2004).

13. Cao, Y., Andreatta, A., Heeger, A. J. \& Smith, P. Influence of chemical polymerization conditions on the properties of polyaniline, polymer, 30, 2305-2311 (1989).

14. Pron, A., Genoud, F., Menardo, C. \& Nechtschein, M. The effect of the oxidation conditions on the chemical polymerization of polyaniline. Synth. Met, 24, 193-201 (1988).

15. Ding, H., Wan, M. \& Wei, Y. Controlling the Diameter of Polyaniline Nanofibers by Adjusting the Oxidant Redox Potential. Adv. Mater, 19, 465-469 (2007).

16. Liu Yuyang, S., Yinghui, W. \& Wei Study on effects of the doping parameters on conductivity of ployaniline film. Journal of Functional Polymers, 4, 35-39 (1999).

17. Stejskal, J., Hlavatá, D., Holler, P. \& Trchová, M. J. Prokeš and I, Polyaniline prepared in the presence of various acids: a conductivity study Sapurina. polymer international, 53, 294-300 (2004).

18. Quillard, S., Louarn, G., Lefrant, S. \& MacDiarmid, A. G. Vibrational analysis of polyaniline: a comparative study of leucoemeraldine, emeraldine and pernigraniline bases. Phys. Rev. B: Condens. Matter, 50, 12496-12508 (1994).

19. Moon, Y. B. et al. X-ray scattering from crystalline polyaniline. Polym. Commun, 30, 196-199 (1989). 
20. Wessling, B. New Insight into Organic Metal Polyaniline Morphology and Structure. Polymers, 2, 786-798 (2010).

21. Stejskal, J., Gilbert, R. G. \& Polyaniline Preparation of a conducting polymer (IUPAC technical report), Pure and Applied Chemistry 2002,74,857-867.

22. Rannou, P. et al. Ageing of PANI: chemical, structural and transport consequences. Synth. Met, 101, 734-737 (1999).

23. Wolter, A., Rannou, P., Travers, J. P., Gilles, B. \& Djurado, D. Model for aging in $\mathrm{HCl}$-protonated polyaniline: Structure, conductivity, and composition studies. Phys. Rev. B: Condens. Matter, 58, 7637 (1998).

24. Mathew, R., Mattes, B. R. \& Espe, M. P. A solid state NMR characterization of cross-linked polyaniline powder. Synth. Met, 131, 141-147 (2002).

25. Cruz-Silva, R. et al. Comparative study of polyaniline films prepared from enzymatically and chemically synthesized polyaniline., 45, 4711-4717 (2004).

26. Trchová, M. et al. Structural and conductivity changes during the pyrolysis of polyaniline base. Polymer Degradation and Stability, 91, 114-121 (2006).

27. He, Y. H. C. M. H. Effect of different doping acids on the structures and conductivity of polyaniline. Journal of South China University of Technology (Natural Science Edition), 5, 21-24 (2003).

28. Kuo, C. W. et al. Doping process effect of polyaniline doped with poly(styrenesulfonic acid) supported platinum for methanol oxidation. Taiwan Inst Chem E, 44, 497-504 (2013).

29. Du, H. Y. et al. Preparation of modified MWCNTs-doped PANI nanorods by oxygen plasma and their ammonia-sensing properties. Journal of Materials Science, 48, 3597-3604 (2013).

30. Zhang, W. L., Liu, Y. D. \& Choi, H. J. Fabrication of semiconducting graphene oxide/polyaniline composite particles and their electrorheological response under an applied electric field., 50, 290296 (2012).

31. Busby, E. et al. Acceptor dependent polaron recombination dynamics in poly 3-hexyl thiophene: Fullerene composite films. Chem. Phys. Lett, 513, 77-83 (2011).

32. Katoch, A. et al. Synthesis of polyaniline/TiO2 hybrid nanoplates via a sol-gel chemical method. Chem. Eng. J, 192, 262-268 (2012).

33. Wu, G. et al. High-performance electroc- atalysts for oxygen reduction derived from polyaniline, iron, and cobalt., 332, 443-447 (2011).

34. Chen, X. et al. Glucose biosensor based on three dimensional ordered macroporous self-doped polyaniline/Prussian blue bicomponent film. Anal. Chim. Acta, 723, 94-100 (2012).

35. Ning, G. Q. et al. Three-dimensional hybrid materials of fish scale-like polyaniline nanosheet arrays on graphene oxide and carbon nanotube for high-performance ultracapacitors., 54, 241-248 (2013).

36. Kamaraj, K. et al. Synthesis of oxalate doped polyaniline and its corrosion protection performance. Journal of Solid State Electrochemistry, 16, 465-471 (2012). 
37. Hu, C. C. \& Chu, C. H. Electrochemical impedance characterization of polyaniline-coated graphite electrode for electrochemical capacitors-efects of film coverage thickness and anions. Journal of Electroanalytical Chemistry, 503, 105-116 (2001).

38. Pałys, B. \& Celuch, P. Redox transformations of polyaniline nanotubes: Cyclic voltammetry, infrared and optical absorption studies. Electrochim. Acta, 51, 4115-4124 (2006).

39. Tawde, S., Mukesh, D. \& Yakhmi, J. V. Redox behavior of polyaniline as influenced by aromatic sulphonate anions: cyclic voltammetry and molecular modeling, Synthetic Metals 2001, 125,401413.

40. Geniès, E. M., Lapkowski, M. \& Penneau, J. F. Cyclic voltammetry of polyaniline: interpretation of the middle peak. Journal of Electroanalytical Chemistry and Interfacial Electrochemistry, 249, 97-107 (1988).

41. DobrevT, Valchanova, I. et al. Investigations of new anodic materials for zinc electrowinning. Transactions of the Institution of Metal Finishing, 87, 136-140 (2009).

42. Xu, R., Wang, J. \& Guo, Z. Pulse Electrodepositon of Ni-W-P-CeO2-SiO2 Composite Coatings. Manufacturing Science and Engineering, 97-101, 1385-1388 (2010).

43. Gospodinova, N. \& Terlemezyan, L. Conducting polymers prepared by oxidative polymerization: polyaniline. Progress in Polymer Science, 23, 1443-1484 (1998).

44. Negi, Y. S. \& Adhyapak, P. V. Development in polyaniline conducting polymers. J Macromol Sci, Polym Rev, 42, 35-53 (2002).

45. Stejskal, J., Sapurina, I. \& Trchova, M. Polyaniline nanostructures and the role of aniline oligomers in their formation. Progress in Polymer Science, 35, 1420-1481 (2010).

46. Huang, J. X. \& Kaner, R. B. A general chemical route to polyaniline nanofibers. Journal of the American Chemical Society, 126, 851-855 (2004).

47. Trchová, M. et al. FTIR spectroscopic and conductivity study of the thermal degradation of polyaniline films. Polymer Degradation and Stability, 86, 179-185 (2004).

\section{Figures}




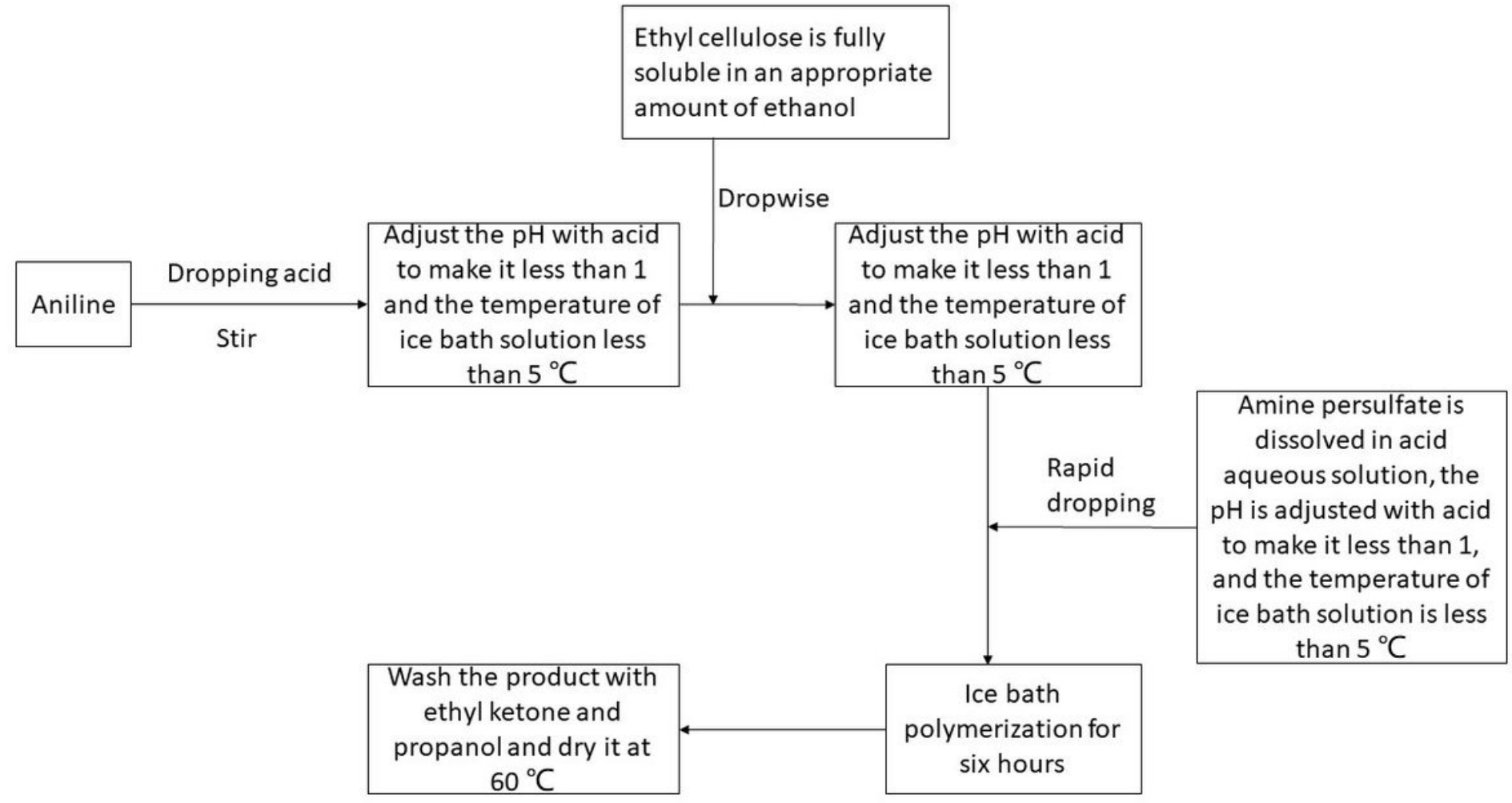

\section{Figure 1}

Schematic illustration of preparing polyaniline nanofibers

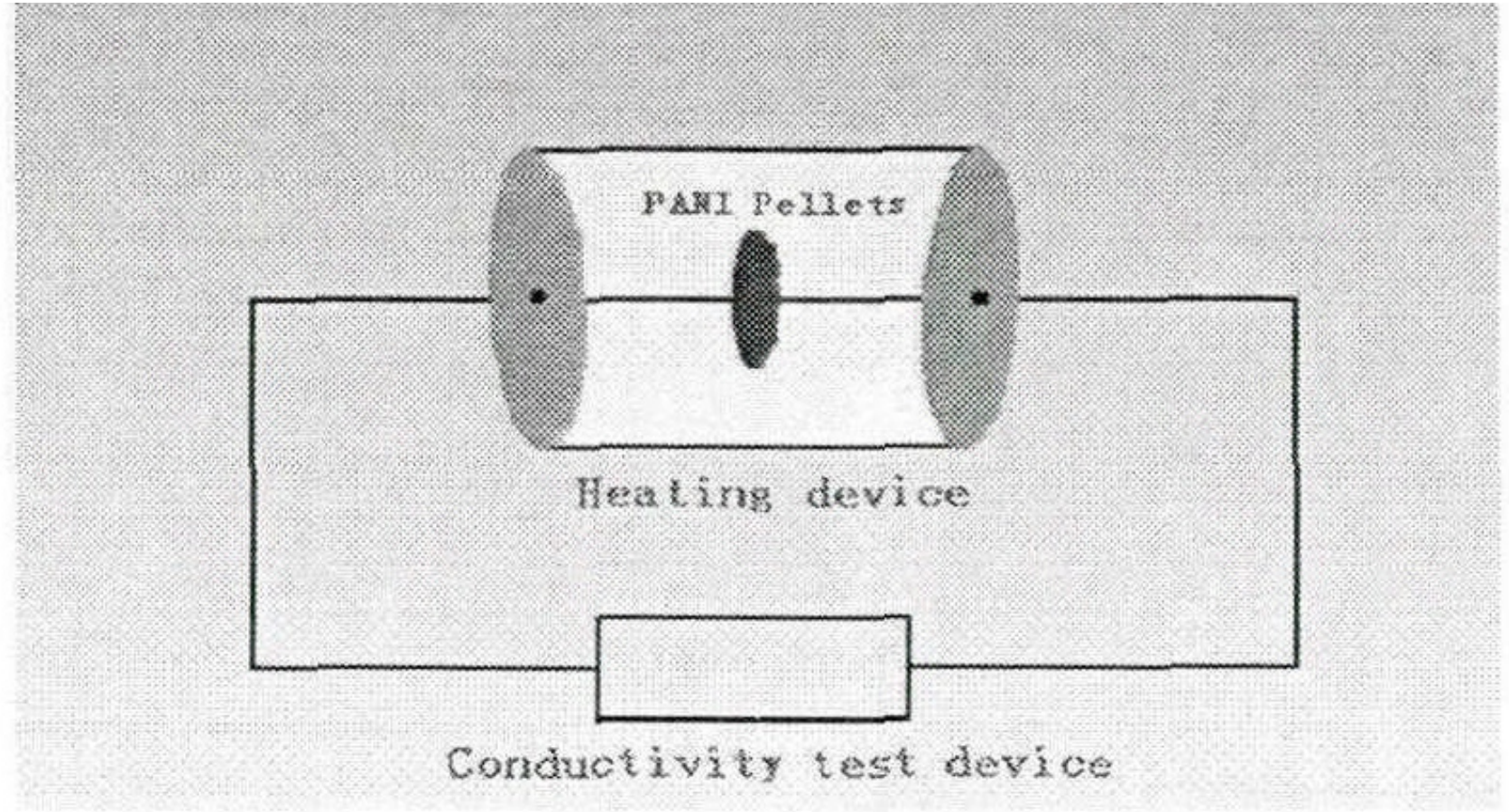

Figure 2

The experimental apparatus for measuring the thermal stability of the conductivity of polyaniline 

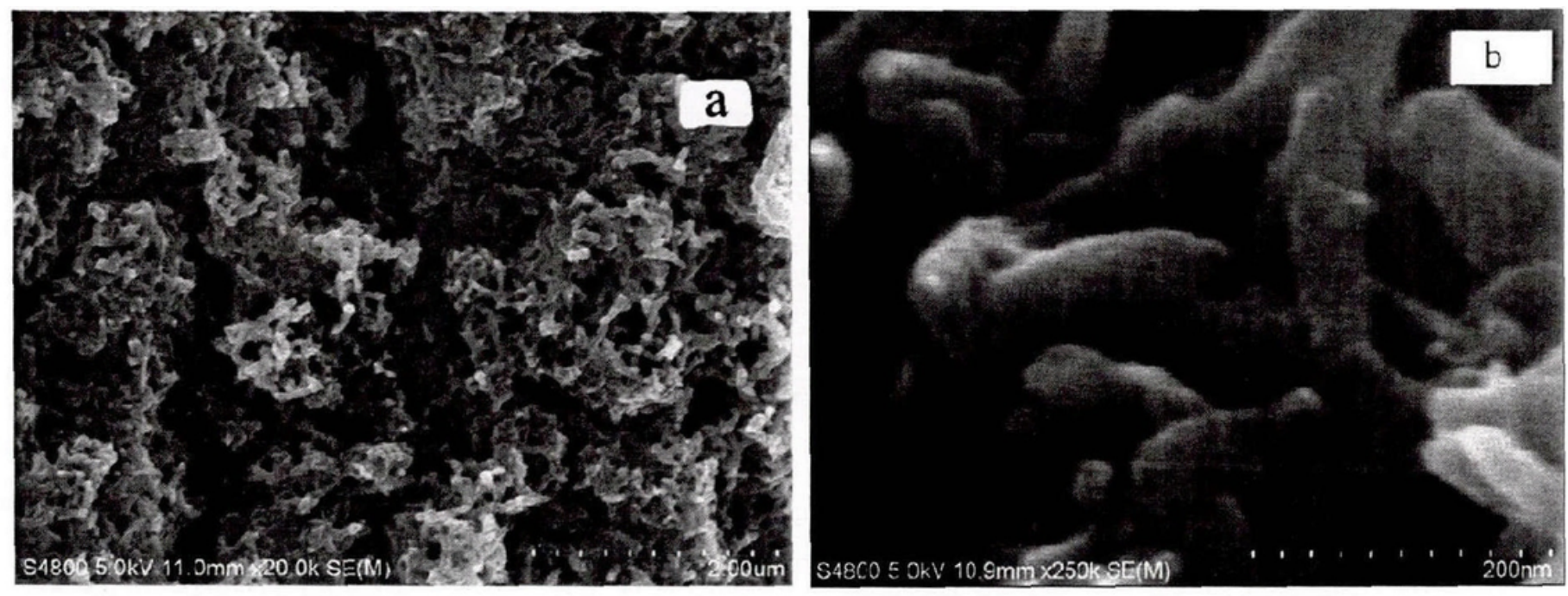

\section{Figure 3}

The SEM images of PANI nanofibers. The magniEcation for $a$ and $b$ are different
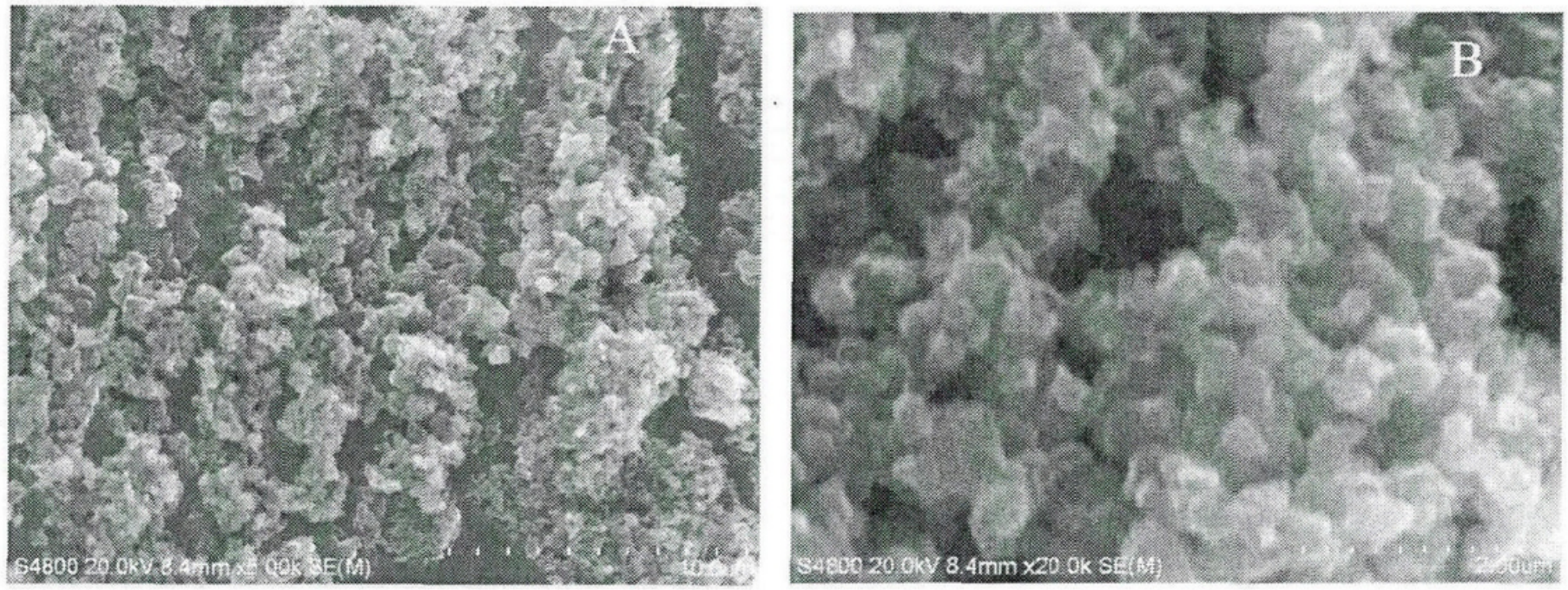

Figure 4

SEM image of PANI prepared without template. The magnification for A and B are different. 

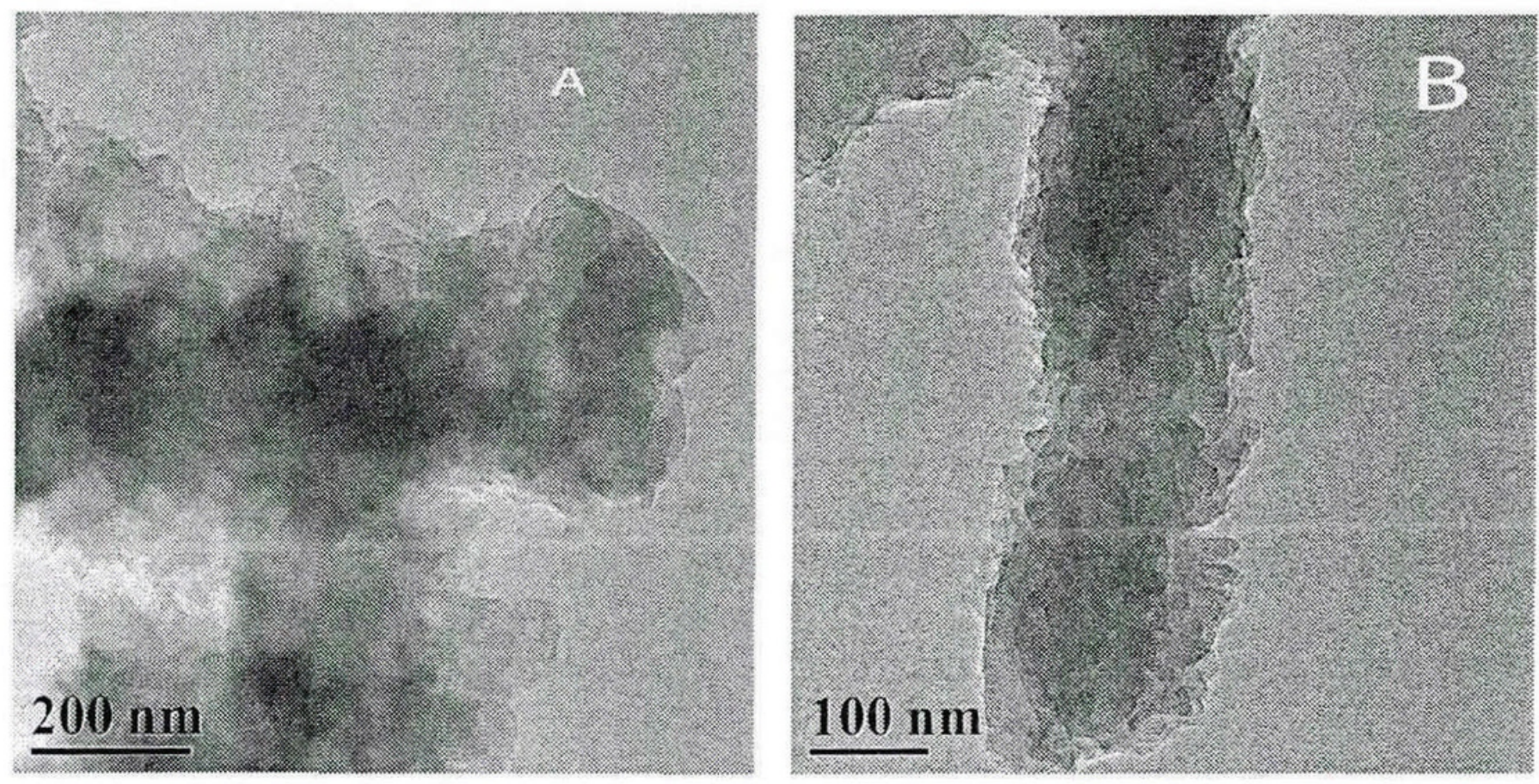

\section{Figure 5}

Figure A is SEM image of PANI prepared without template. Figure A is SEM image of PANI nanofiber
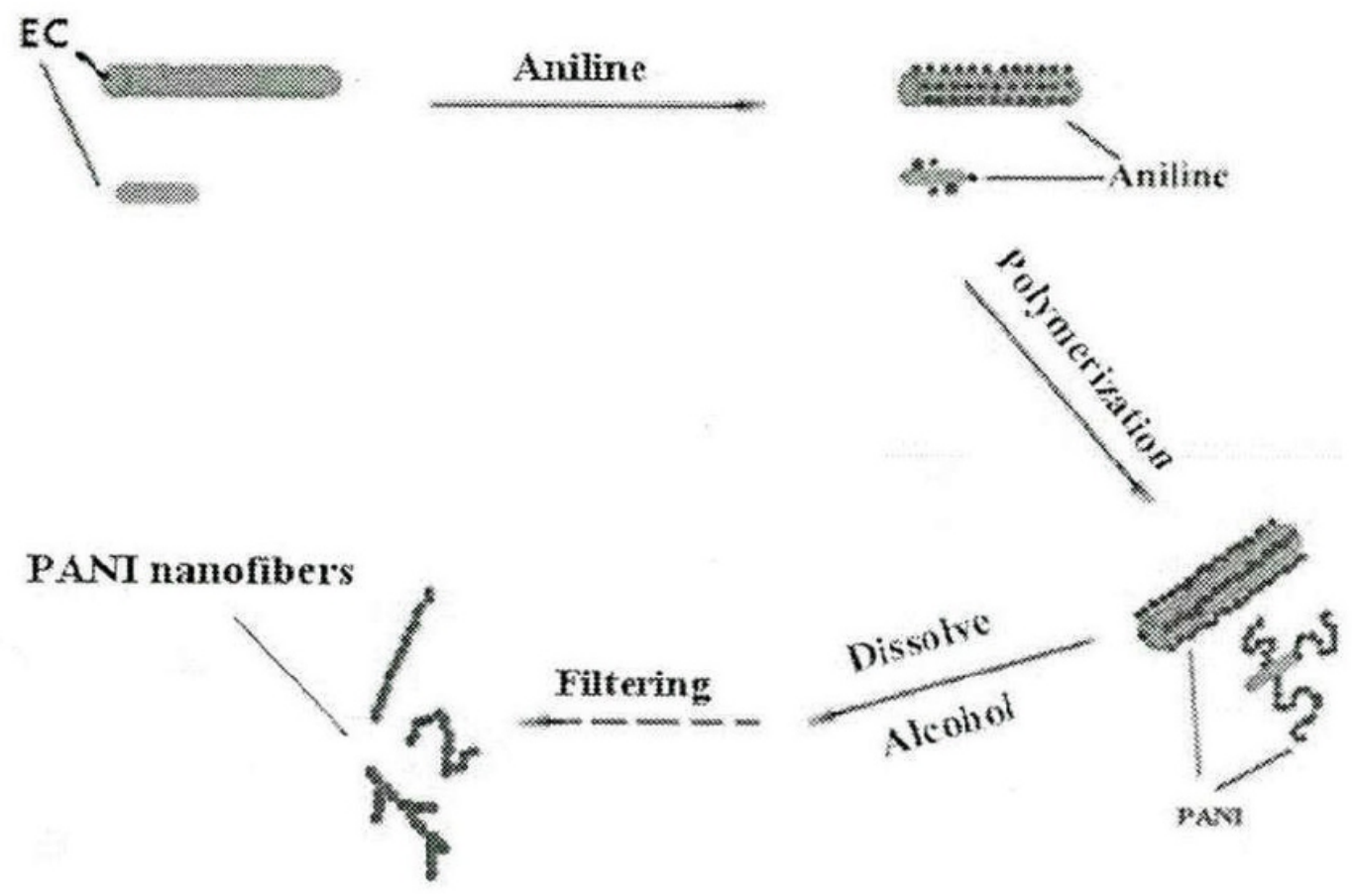

Figure 6

Schematic illustration of PANI nanofiber growth. 


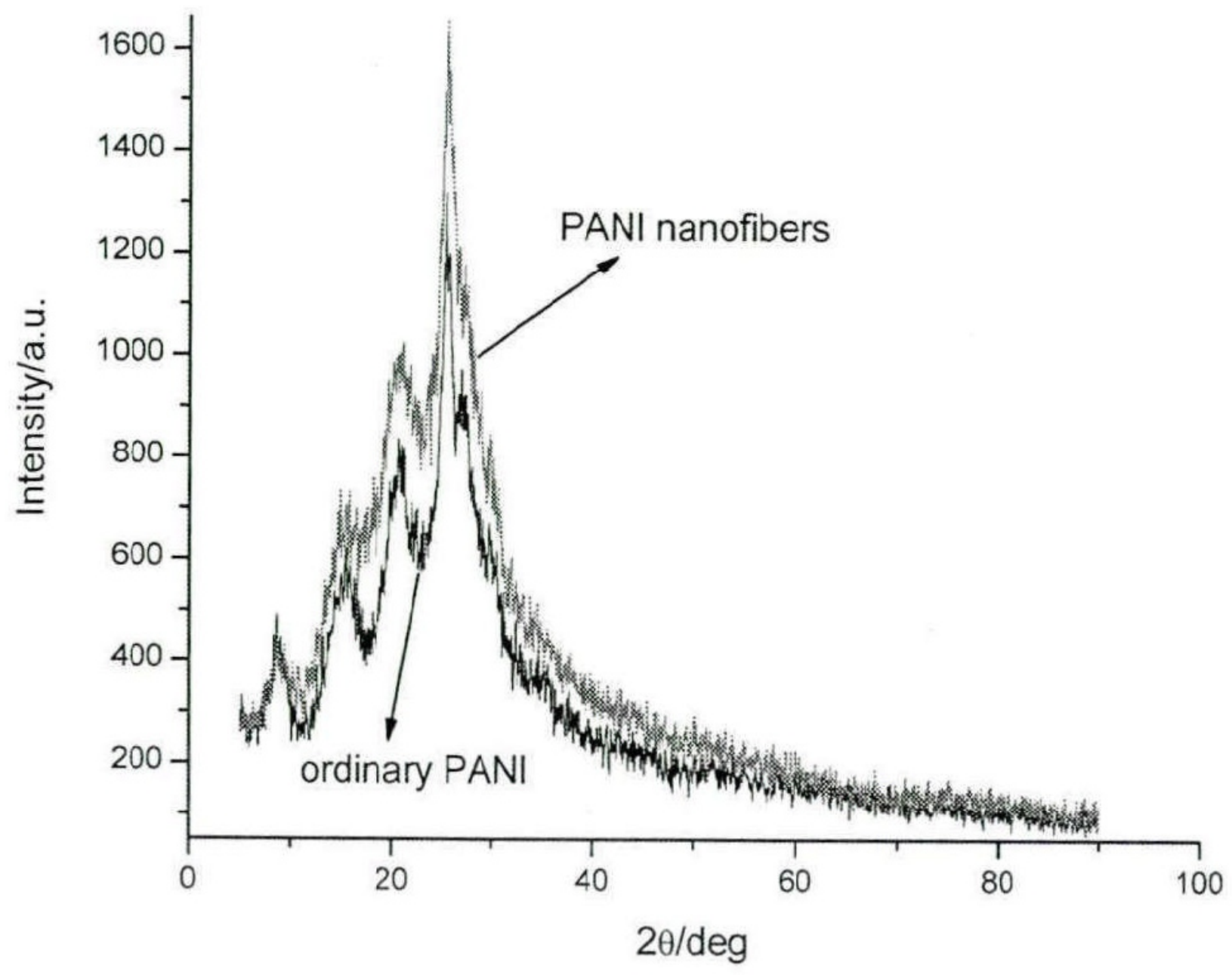

Figure 7

XRD patterns of ordinary PANI and PANI nanofiber samples 

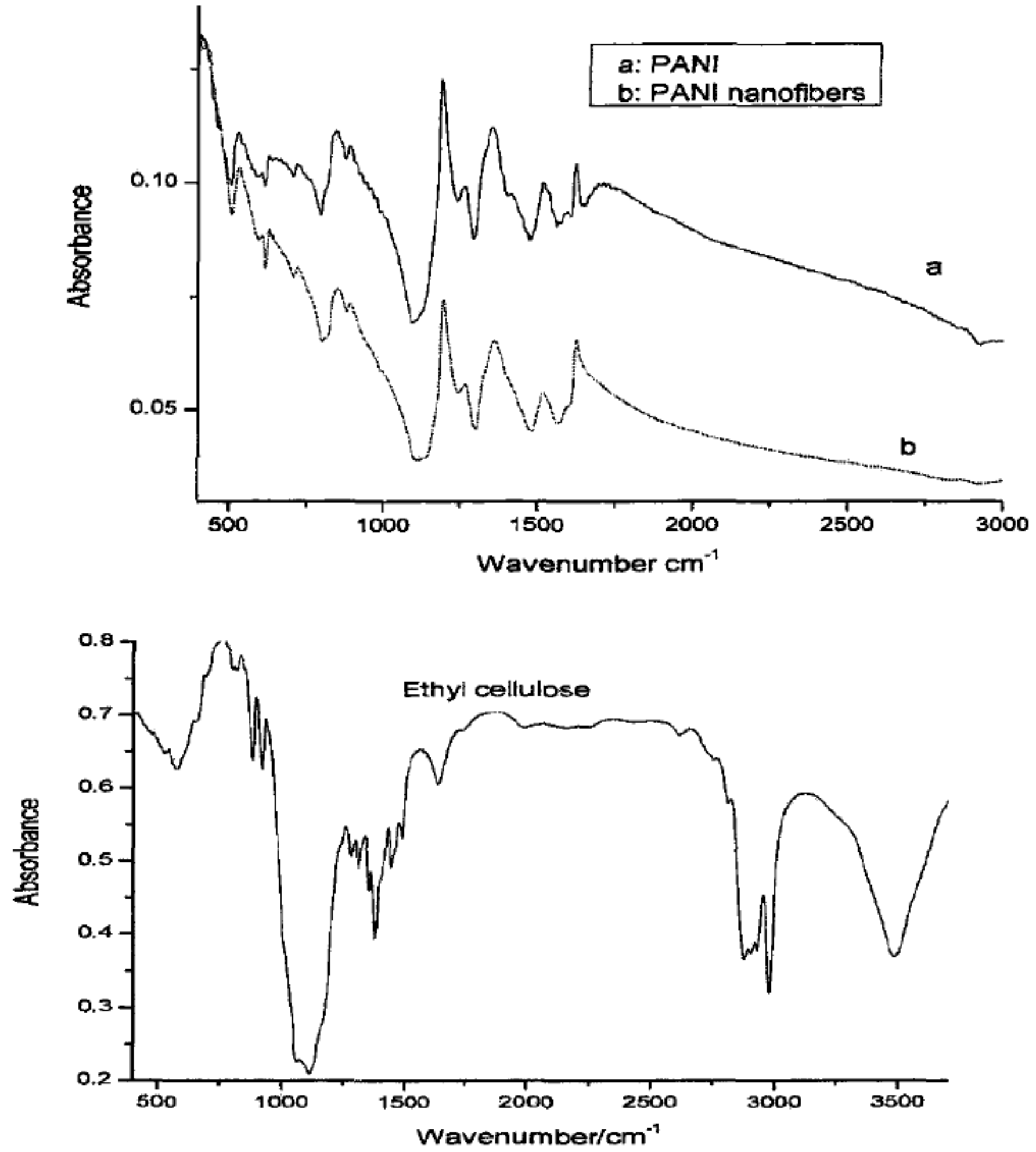

Figure 8

FTIR spectra of PANI nanofibers, PANI prepared without template and pure ethyl cellulose 

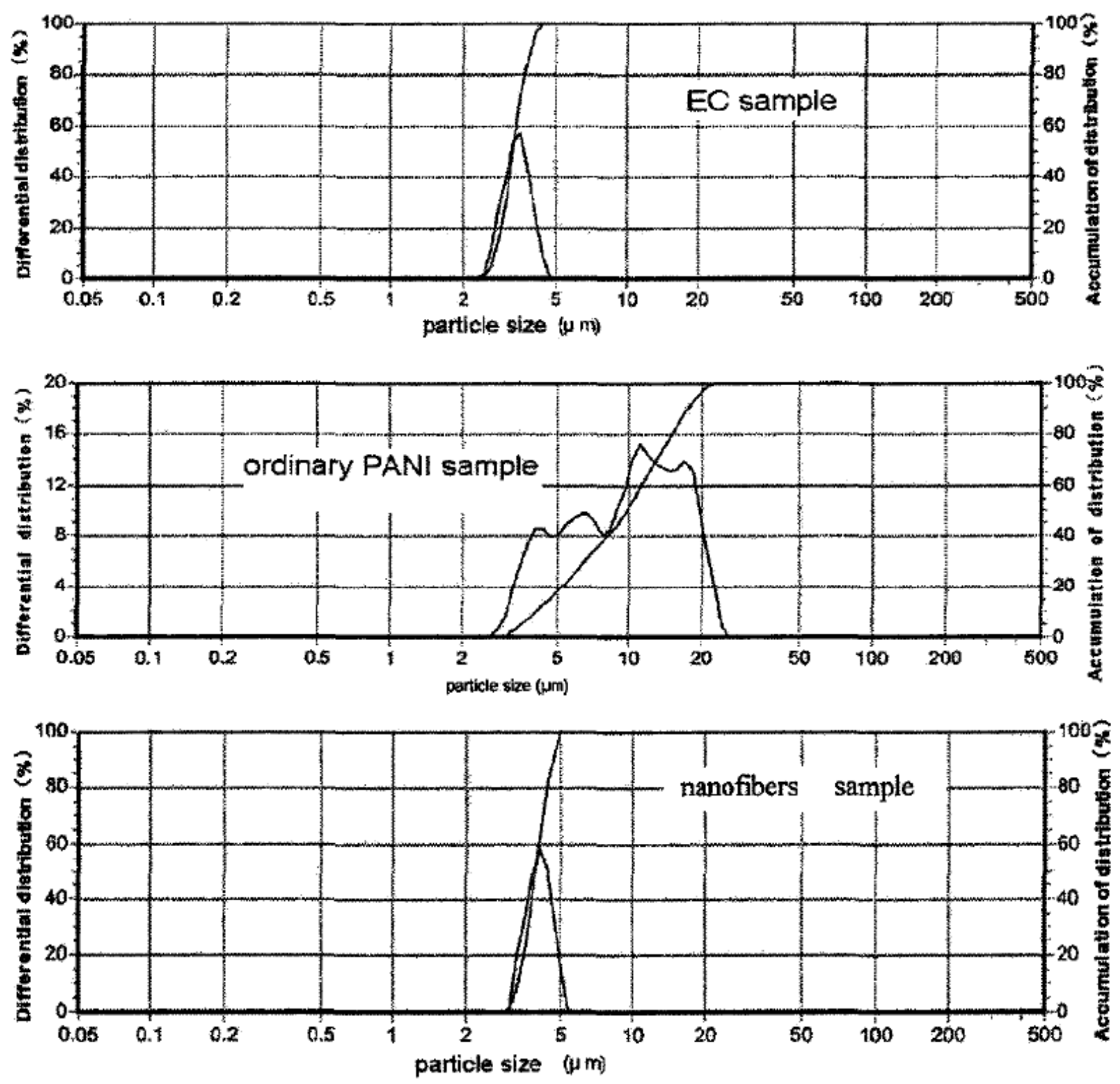

Figure 9

Particle size distribution of ethyl cellulose, ordinary PANI, and PANI nanofiber samples 


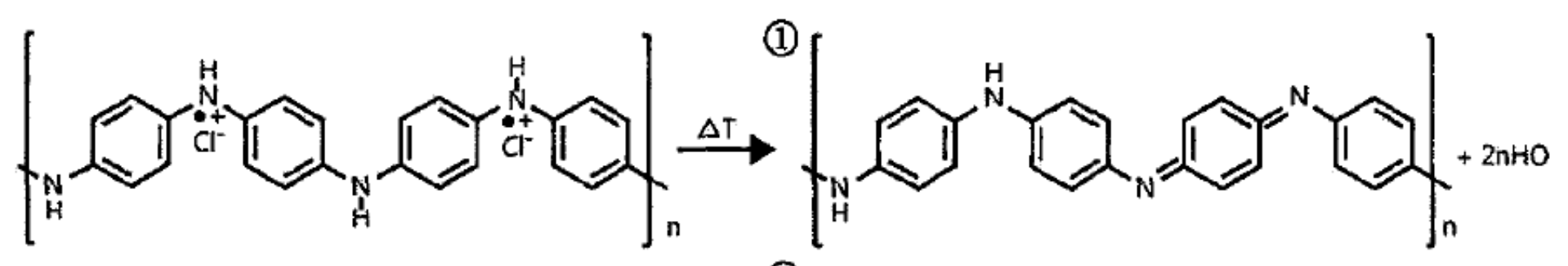<smiles>C=C[Te][Te][Te][Te][Te]C(C)(C)C</smiles>

Figure 10

The degradation for PANI molecule under $200^{\circ} \mathrm{C}$

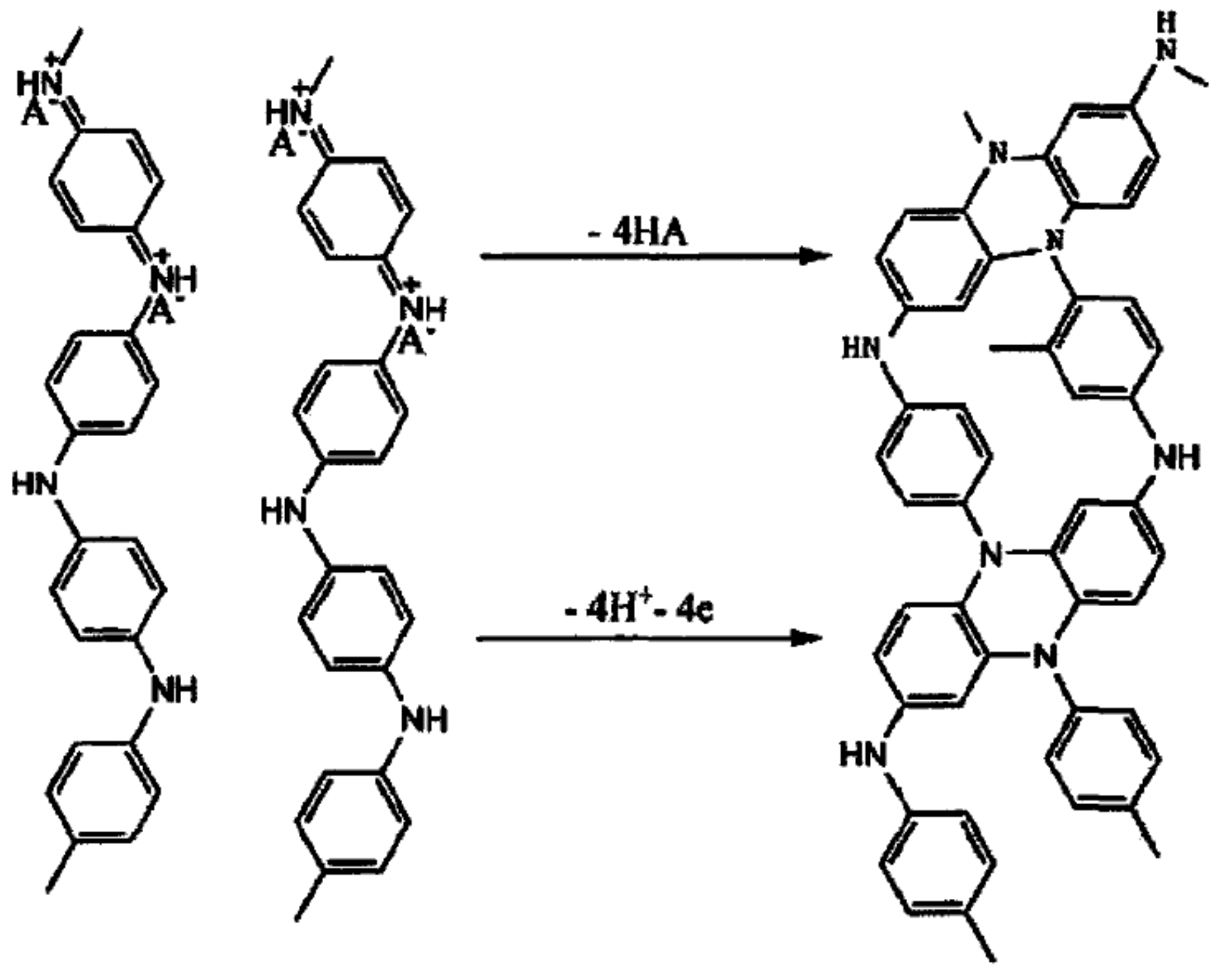

Figure 11 
The process for PANI molecule crosslinking
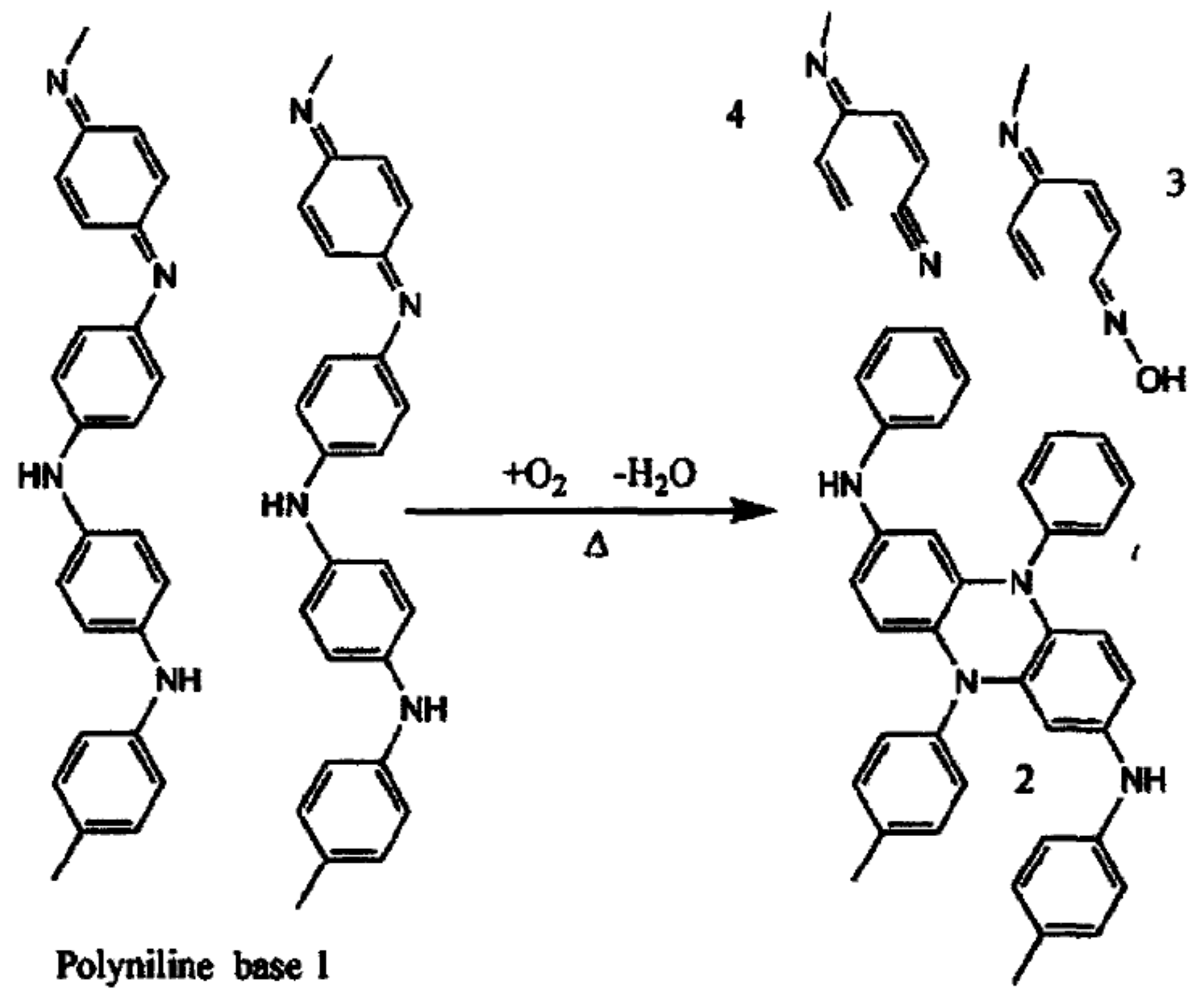

Figure 12

The abruption for PANI molecular chain under high temperature 


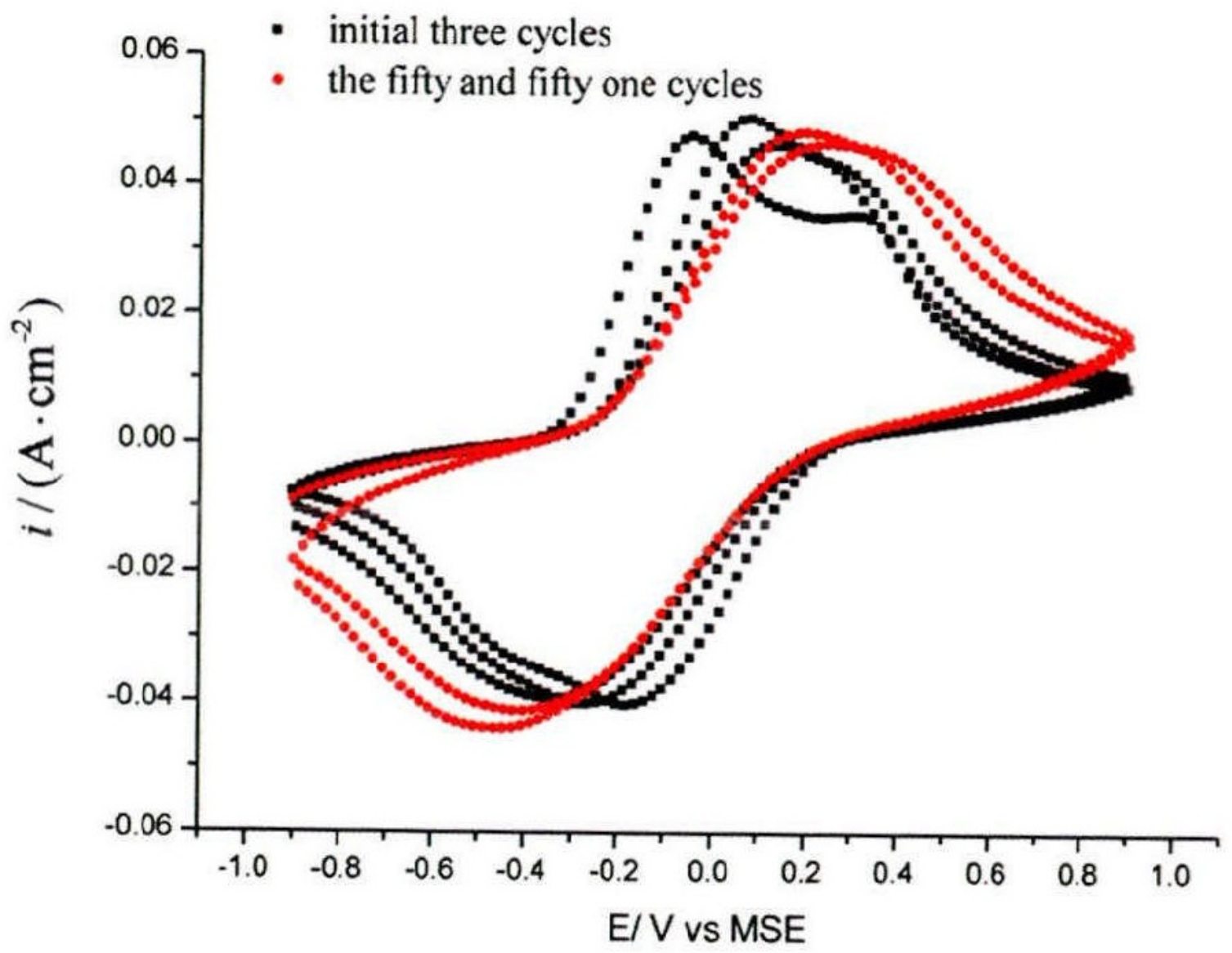

Figure 13

The comparison for the $\mathrm{CV}$ curves of $\mathrm{PANI}-\mathrm{HCl}$ in $\mathrm{H} 2 \mathrm{SO} 4$ medium 


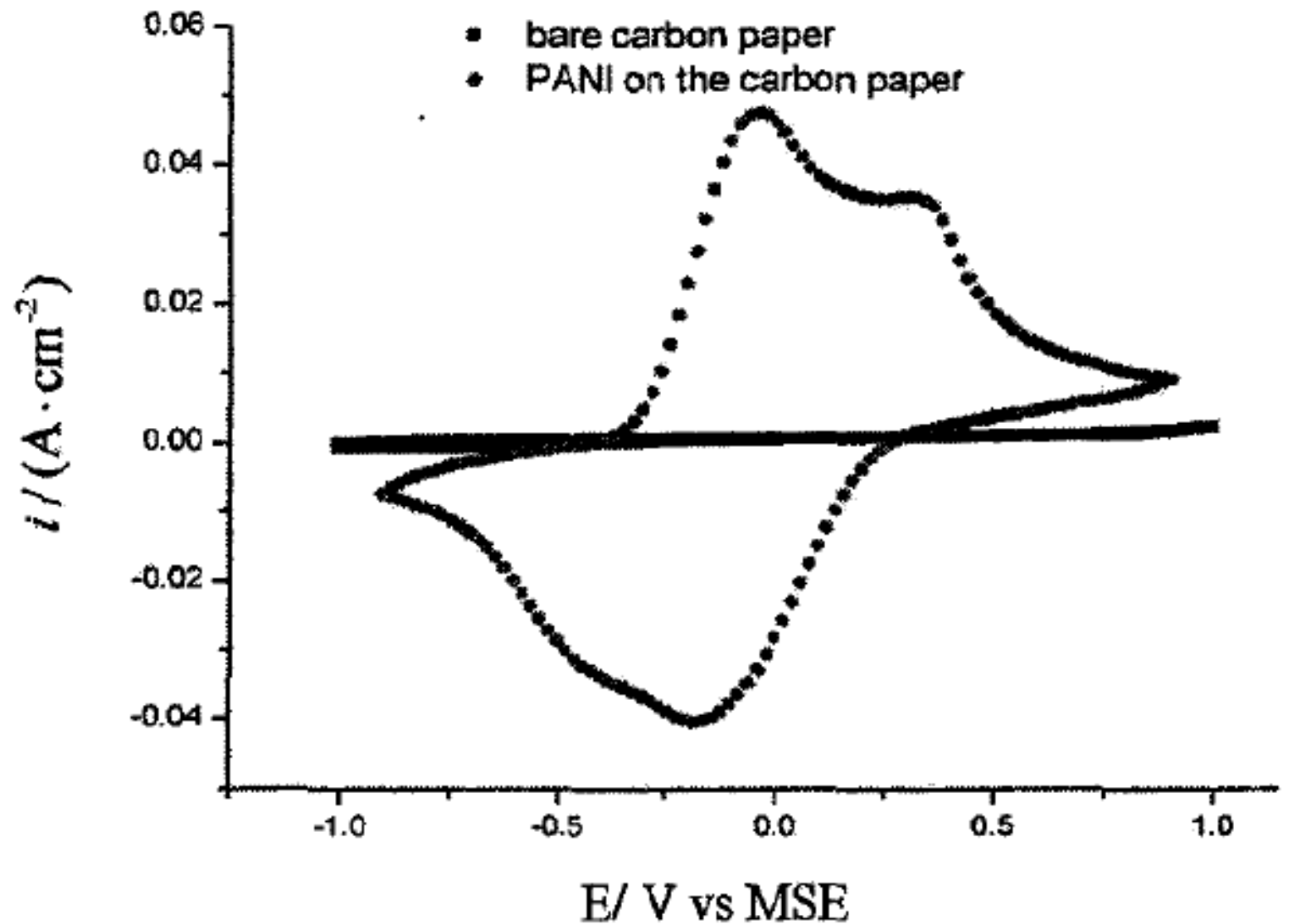

Figure 14

Cyclic voltammetry of Nanoscale polyaniline in the evolution of oxygen environment 


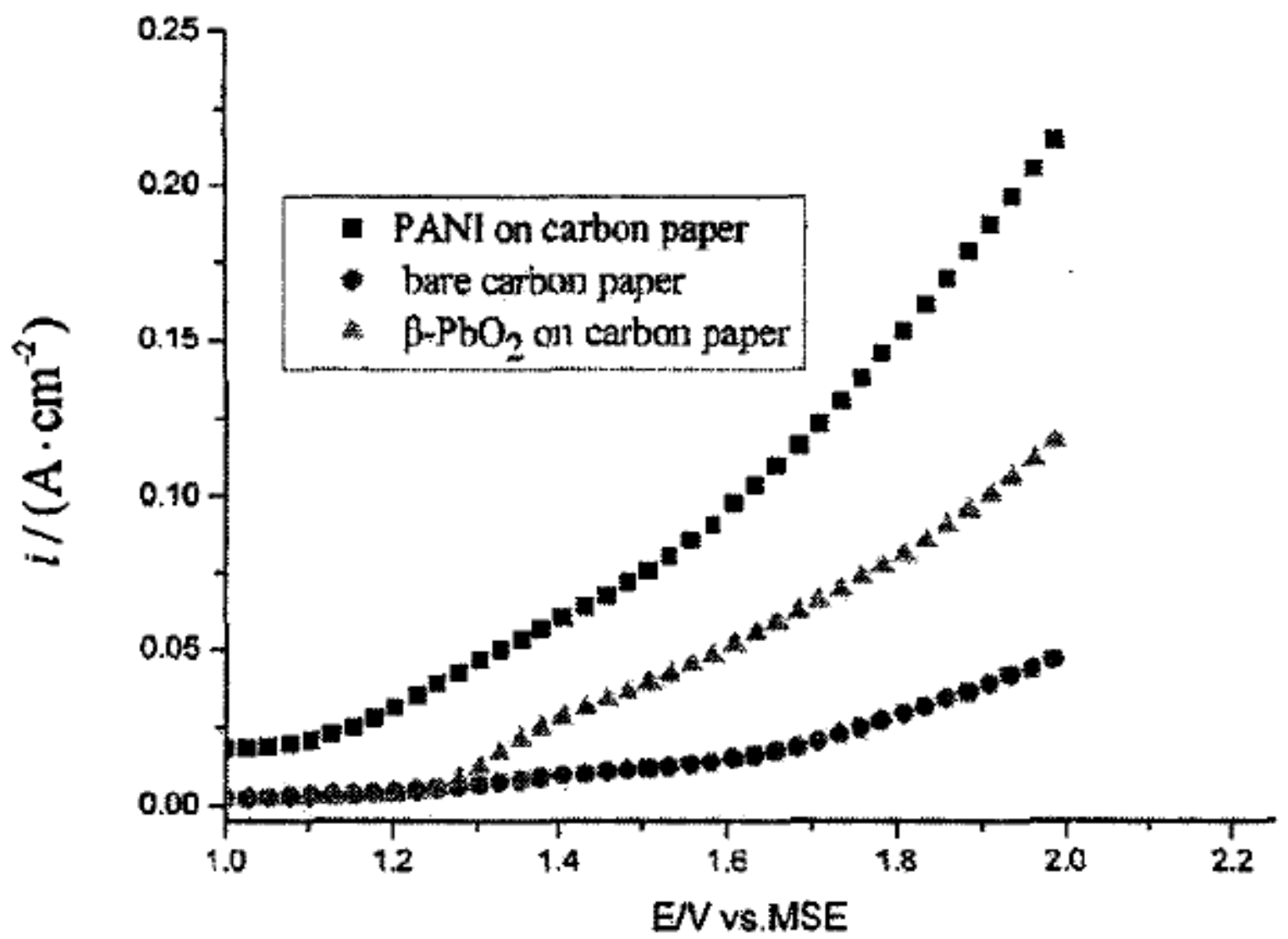

Figure 15

Steady-state polarization curves of oxygen evolution of nanoscale polyaniline and $\beta-\mathrm{PbO} 2$ 


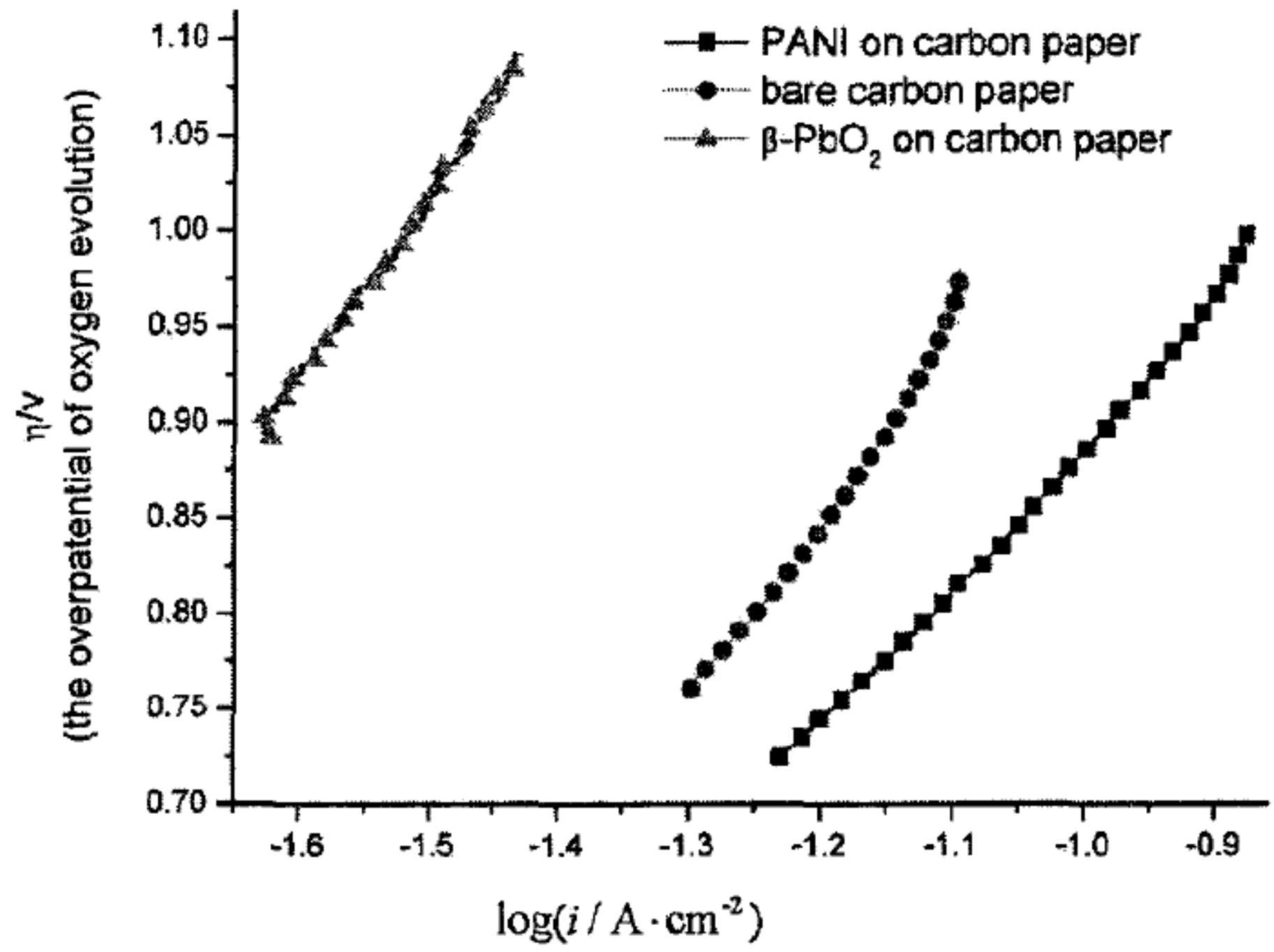

Figure 16

The curves of oxygen evolution overpotential and Igi about the three anodes (PANI on carbon paper, $\beta$ $\mathrm{PbO} 2$ on carbon paper and bare carbon paper) 


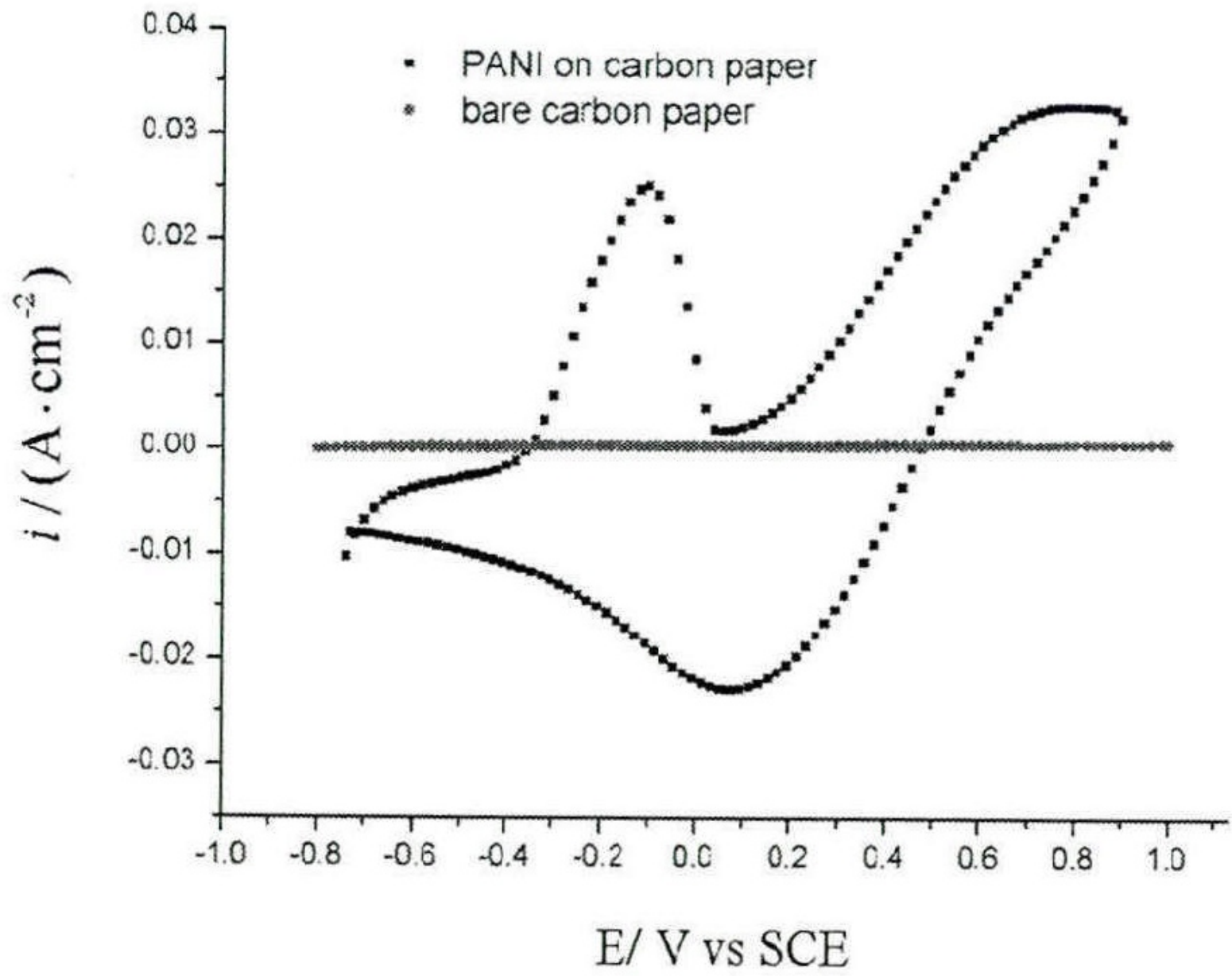

Figure 17

Cyclic voltamrnetry of Nanoscale polyaniline in the evolution of Chlorineenmronment 


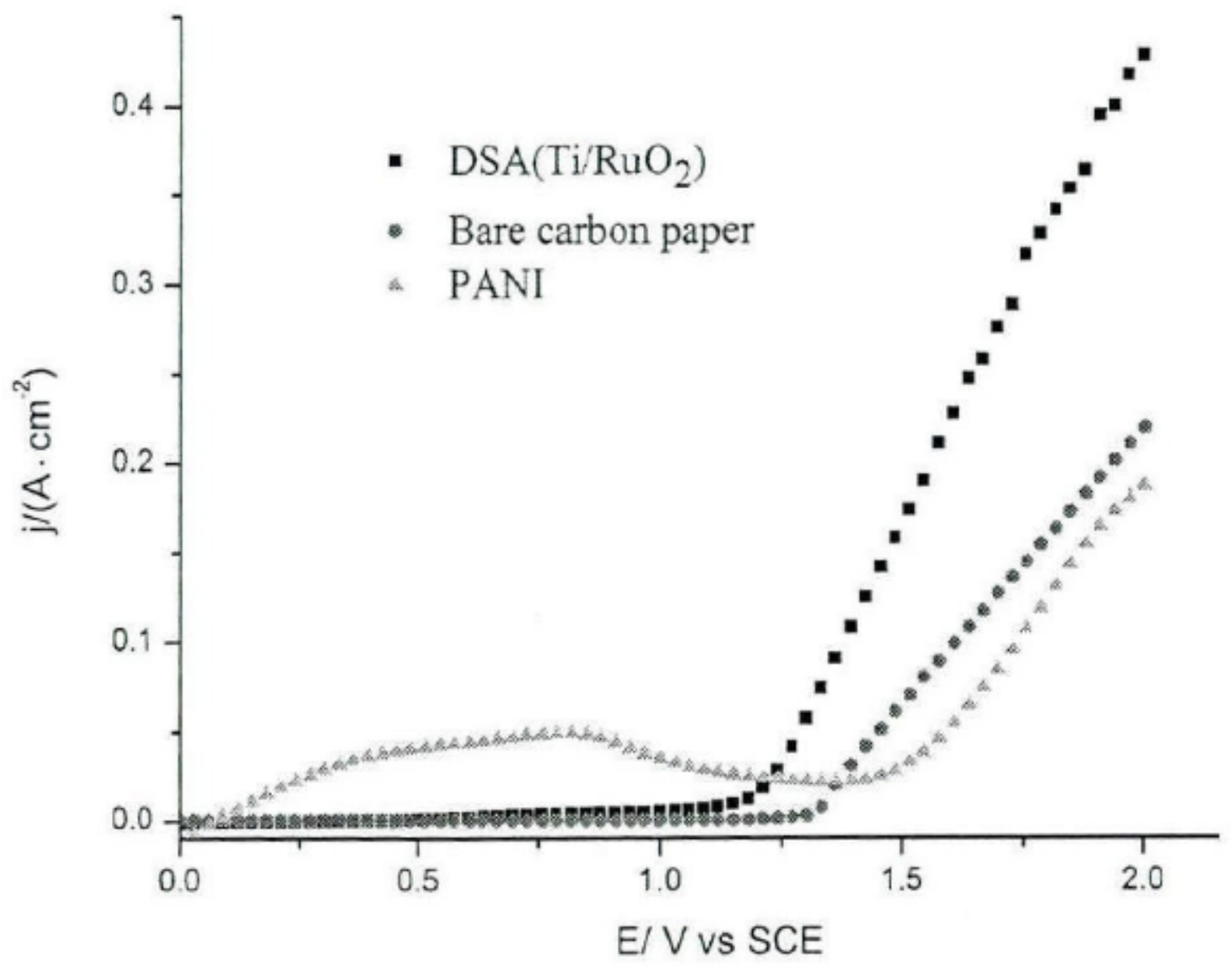

Figure 18

Steady-state polarization curves for oxygen evolution of Nanoscale polyaniline in the evolution of chlorine environment 


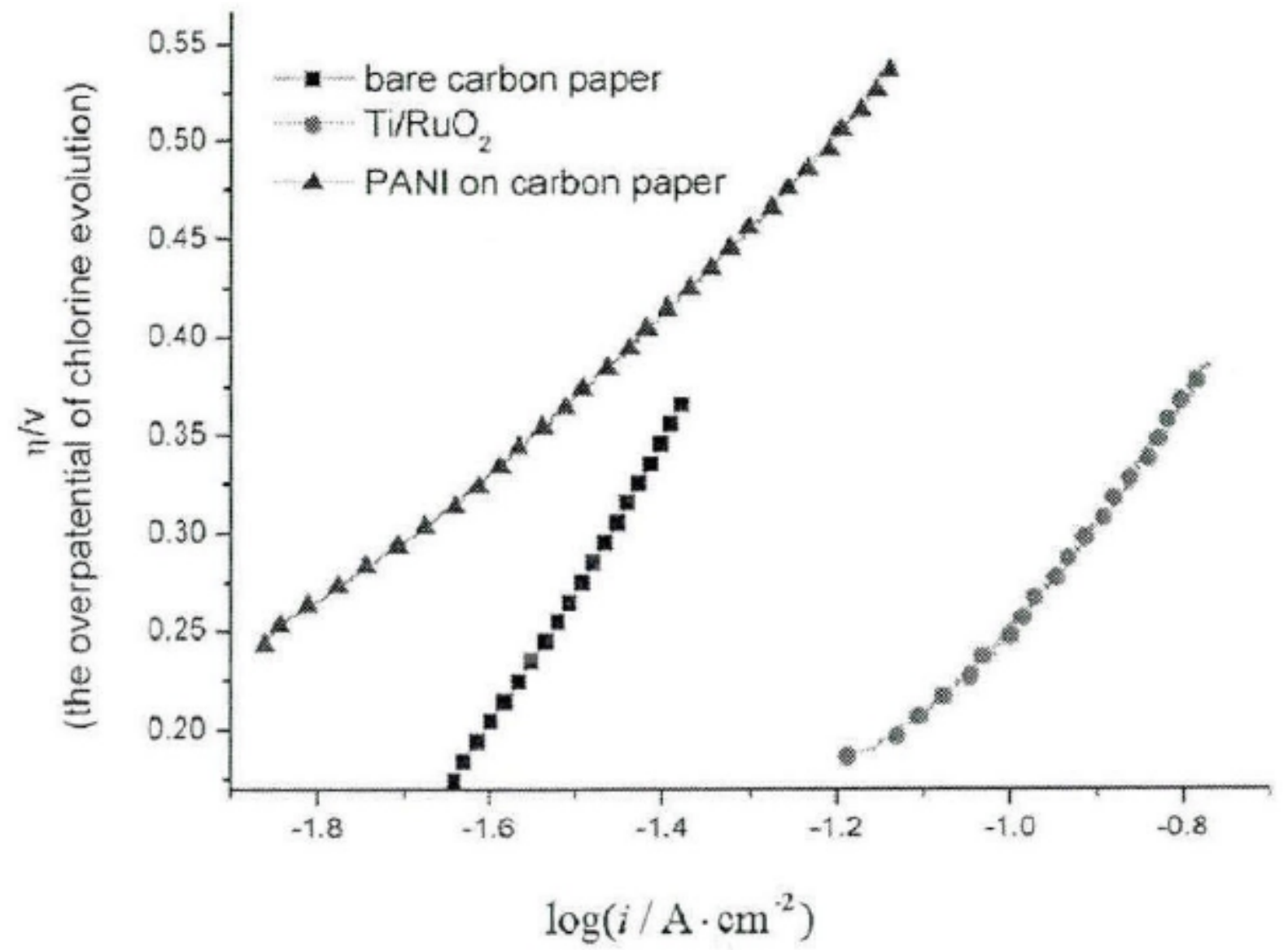

Figure 19

The curves of chlorine evolution overpotential and Igi about the three anodes (PANI on carbon paper, $\mathrm{Ti} / \mathrm{RuO} 2$ and bare carbon paper) 